\title{
Artículos
}

\section{La concentración de la actividad económica en El Salvador ${ }^{1}$}

\author{
Aquiles Montoya ${ }^{2}$
}

\begin{abstract}
La estructura de la mayor parte de la actividad económica de El Salvador está sumamente concentrada. El objetivo principal de este artículo es demostrar que la concentración estadístico-estructural conlleva a una concentración del ingreso, lo cual a su vez origina mercados raquíticos que impiden el crecimiento de la economía en cuanto a generación de empleo e ingresos suficientes que abatan la pobreza. Por tanto, es urgente y necesario mejorar la distribución del ingreso para posibilitar un crecimiento endógeno y autosostenido.
\end{abstract}

Resumen

\section{Introducción}

Este artículo es la continuación de otro publicado el año pasado titulado "La concentración en la industria manufacturera" y aunque ciertamente avanza en el estudio y conocimiento de la realidad, no agota la problemática que se analiza. Por tal razón todavía no ha sido posible verificar la hipótesis fundamental que se formuló entonces; sin embargo, se proporciona otra información internacional, -que puede ayudar a comprender mejor la realidad y el contenido de nuestras for- mulaciones - así como nacional acerca de la distribución del ingreso, el cual es consecuencia de la concentración estadístico-estructural.

El cuerpo de la investigación se centra en la información proporcionada por los VI Censos Económicos, elaborados durante 1992 y publicados en 1993. Hemos utilizado alguna información que se encuentra en sus seis volúmenes, con lo cual hemos podido presentar la estructura de la mayor parte de la actividad económica que nos revela un elevado grado de concentración. Desafortunada-

1. El autor agradece la lectura y los comentarios de Rafael Pleitez y Alvaro Trigueros.

2. Catedrático del Departamento de Economía de la Universidad Centroamericana "José Simeón Cañas". 
mente no hubo censo para el agro ni para la construcción y el transporte. La dificultad que se tuvo con el primero, así como con la ausencia de información sobre la banca, ha sido posible resolverla de manera parcial, pero no podemos decir lo mismo csobre el transporte y la construcción. A fin de enfrentar la dificultad de.cobertura que presenta el censo, hemos acudido a cúalquiera otra fuente disponible, como por ejemplo la que proporciona el Banco Central de Reserva, la Superintendencia del Sistema Financiero, el Ministerio de Hacienda, etc. Y también presentamos información analítica sobre la concentración geográfica de la manufactura y el comercio en el Área Metropolitana de San Salvador (AMSS), que son los sectores que ha estudiado la DIGESTYC y que aparecen en el VI Censo.

Se trata de una investigación de carácter documental y la principal razón de realizarla radica en el interés de demostrar que cuando en una economía existe concentración estadístico-estructural, esto se traduce en una concentración del ingreso, situación que se convierte en una limitante muy seria para abolir la pobreza. En otras palabras, significa que la economía puede crecer a tasas muy elevadas y, sin embargo, siempre existirá pobreza debido a que el ingreso está distribuido inequitativamente.

La situación anterior, que incluso puede presentarse en economías ricas como las del primer mundo, se manifiesta como un paso de la simple pobreza a la miseria cuando se trata de países económicamente subdesarrollados como el nuestro. De manera que para combatir la pobreza no basta con que se incremente el empleo, si se mantiene una desigual distribución de la riqueza, aunque hacerlo sería un factor de suma importancia para combatir la miseria. Es obvio que las personas que tienen un empleo y un salario ya no son miserables, aunque sigan siendo pobres; sin embargo, pese a lo que afirman algunos, para incrementar el empleo no basta con que se invierta en educación y salud. Es posible tener un pueblo educado y hasta quizá sin que padezca de algunas enfermedades, $y$ pese a ello que no cuente con un empleo y tampoco con ingresos.
El mostrar la concentración existente en la mayoría de las actividades económicas no tiene como finalidad afirmar, sugerir o insinuar la necesidad de afectaciones en la propiedad con medidas de carácter populista. Para enfrentar problemas de pobreza estructural no bastan las medidas que tienen por origen razonamientos mecánicos. Es por ello que nuestro interés radica, más bien, en señalar que existen límites provenientes de la naturaleza propia del sistema y que, por tanto, no se puede actuar de manera inocente o aceptar ingenuamente falsas salidas a los problemas, lo cual no excluye la posibilidad de sugerir algunas medidas correctivas que contribuyan a disminuir la miseria $e$, inclusive, la pobreza.

Dicen que la democracia exige de mucha información y conocimiento acerca de la realidad, de manera que si somos partidarios de la misma, actuemos en consecuencia para no vivir una simple caricatura de ésta, que ha sido lo usual en nuestro medio.

\section{Un vistazo a nivel mundial a la concentra- ción y centralización}

La tendencia del capitalismo es hacia la concentración y centralización del capital, lo cual constituye uno de los planteamientos fundamentales de Karl Marx en El Capital, desarrollado bajo el acápite de La Ley de Acumulación del Capital ${ }^{3}$. Y en una primera aproximación a esta problemática, que hiciéramos el año pasado, sosteníamos:

$Y$ es que el proceso de crecimiento de una empresa fundamentado en la reinversión de sus ganancias, que es lo que se tipifica como proceso de concentración del capital, es obviamente, un proceso que se corresponde con la normalidad capitalista. Este proceso que tiene como resultado que el capitalista controle una mayor cantidad de empleados, así como una mayor cantidad de medios de producción y de productos, lo cual se conoce como concentración del capital, no puede ser más que normal dentro de la lógica del capitalismo ${ }^{4}$.

En otro orden de ideas, pero como una clara consecuencia de la dinámica capitalista, a nivel

3. K. Marx, El Capital, Tomo I, Cap. XXIII. Para una lectura más rápida puede consultar, A. Montoya, Economia Crítica, Cap. 11, San Salvador: Editores Críticos, 1998.

4. A. Montoya, "La concentración en la industria manufacturera", ECA, septiembre, 1998, p. 771. 
mundial existe una clara tendencia hacia la concentración del ingreso, fenómeno que es observable tanto entre los países desarrollados como entre los subdesarrollados, así lo reporta el PNUD:

En 1960, el 20 por ciento de la población mundial que vivía en los países más ricos tenía 30 veces el ingreso del 20 por ciento más pobre, y en 1995 tenía 82 veces ese ingreso... En Brasil, el 50 por ciento más pobre de la población recibió el 18 por ciento del ingreso nacional en 1960 y su participación se redujo al 11.6 por ciento en 1995 . El 10 por ciento más rico recibió el 54 por ciento del ingreso nacional en 1960 , y su participación se elevó al 63 por ciento en $1995^{5}$.

En otras palabras, la cita anterior nos confirma esa vieja tesis de que en el capitalismo, los ricos se hacen cada vez más ricos y los pobres cada vez más pobres.

Pero concentración y centralización son como dos caras de la misma moneda, no existe la una sin la otra, aunque los mecanismos sean muy diferentes, la concentración se origina desde el interior de la empresa capitalista, en cambio la centralización ocurre gracias a las empresas externas o a las otras empresas, eso es lo que sosteníamos en otro trabajo:

El crecimiento de las empresas a veces no se logra mediante el proceso de reinversión de utilidades,... sino que ocurre por absorción de otras empresas o por fusión con las mismas. A este proceso para diferenciarlo del primero se le denomina: centralización del capital ${ }^{6}$.

Ejemplos de centralización del capital los tuvimos de manera masiva el año pasado, cuando ocurrieron 200 fusiones por semana, como lo informa Geoffrey Colvin en el artículo "El Año de las Megafusiones", y donde a su vez señala que el año pasado ocurrieron 8 de las 10 fusiones más importantes de todos los tiempos, las cuales van desde los 40 mil millones hasta los 86 mil millones de dólares:

- Exxon y Mobil Oil, 86 mil millones de dólares.
- Travelers Group y Citicorp, 73 mil millones de dólares.

- SBC Comunications y Ameritech, $72 \mathrm{mil} \mathrm{mi-}$ llones de dólares.

- Bell Atlantic y GTE, 71,mil millones de dólares.

- AT\&T y Tele-Comunications, 70 mil millones de dólares.

- Nations Bank y Bank of America, 62 mil millones de dólares.

- British Petroleum y Amoco, 55 mil millones de dólares.

- Damler-Benz y Chysler, 40 mil millones de dólares.

El total de las 8 fusiones asciende a $529 \mathrm{mil}$ millones de dólares que, como ya lo señalábamos, constituyen las mayores de todos los tiempos. Ahora bien, del total de fusiones que se llevaron a cabo durante 1998, según la fuente ya citada, el 58 por ciento ha ocurrido en Estados Unidos, el 14 por ciento entre empresas extranjeras y de Estados Unidos, y el 28 por ciento fuera de Estados Unidos.

Pero adicionalmente encontramos que la concentración de la riqueza es tal que, como lo enuncia el Informe Sobre Desarrollo Humano $1998 \mathrm{del}$ PNUD, “... los 225 habitantes más ricos del mundo tienen una riqueza combinada superior al billón de dólares, igual al ingreso anual del 47 por ciento más pobre de la población mundial (2 500 millones de habitantes)"' . Y continúa: "Las tres personas más ricas tienen activos que superan el Producto Interno Bruto combinado de los 48 países menos adelantados. Las quince personas más ricas tienen activos que superan el Producto Interno Bruto total del África del sur del Sahara"".

Pero para tener una visión más clara de la concentración de la riqueza - y agregaríamos que para mostrar lo absurdo del sistema capitalista - ocurre que:

Se estima que el costo de lograr y mantener acceso universal a la enseñanza básica para todos, atención básica de salud para todos, atención de salud reproductiva para todas las mujeres, alimentación suficiente para todos y agua

5. PNUD, Informe sobre Desarrollo Humano 1998, p. 29.

6. Op. cit., p. 772.

7. Geoffrey Calvin, "El Año de las Megafusiones", Fortune Américas, El Diario de Hoy, 13 de enero de 1999.

8. Op. cit., Informe sobre Desarrollo Humano 1998, p. 30.

9. Ibid. 
limpia y saneamiento para todos es aproximadamente de 44 mil millones de dólares por año. Esto es inferior al 4 por ciento de la riqueza combinada de las 225 personas más ricas del mundo" ${ }^{11}$.

Y pese a significar tan poco dentro de la magnitud de la riqueza acumulada por tan pocas personas, los pueblos pobres del mundo, más de 2500 millones, no satisfacen esa serie de necesidades básicas antes mencionadas. Y ello de alguna manera es así porque existen 225 personas que concentran tantísima riqueza, al punto de convertirse en un escándalo.

De esas 225 personas más ricas: 60 corresponden a Estados Unidos, 21 a Alemania, 14 a Japón y aunque parezca increíble: 22 son de América Latina y el Caribe ${ }^{11}$. Nuestros pobres pueblos no es que no tengan riqueza, sino que la misma está mal distribuida o muy concentrada. Por ello es que la CEPAL sostiene:

La distribución del ingreso predominante en los países latinoamericanos determina que la región sea considerada, en el ámbito mundial, como una de las más rezagadas en términos de equidad $^{12}$.

Parece una obviedad y realmente lo es, esperar que la realidad salvadoreña sea semejante a la realidad mundial y latinoamericana, aunque todo en nuestro medio se dibuje en una dimensión microescalar, lo cual —desafortunadamente - no hace más pequeña la miseria, la injusticia ni el desasosiego en que viven día tras día varios millones de salvadoreños.

\section{La distribución del ingreso en El Salvador}

Una forma de analizar cuál es la distribución del ingreso en el país es mediante la información que hay en las matrices insumo-producto, como por ejemplo la de 1990 publicada por el Banco Central de Reserva (BCR). En ella encontramos cómo se distribuye el valor agregado entre los trabajadores y los empresarios. En otras palabras, nos muestra qué parte de la riqueza generada llega a los trabajadores y qué parte se destina a los empresarios -además de la parte que es apropiada por el gobiemo-. El resultado es que los empresarios, que son muchísimo menos que los trabajadores, se apropian de casi el doble de lo que se les paga a los trabajadores. Para 1990, la distribución a nivel global fue la siguiente:

Remuneraciones a los trabajadores $32.5 \%$

Excedente bruto de explotación $63.0 \%$

Impuestos indirectos netos de subsidios $\quad 4.5 \%$ Valor agregado

$100.0 \%$

Aparte de toda una serie de reflexiones de carácter ético que se pueden hacer sobre el particular, hay que destacar que esa estructura de los ingresos se convierte en una limitante de carácter económico para el mismo crecimiento de la economía, ya que dicha distribución concentrada del ingreso se traduce en una reducida demanda de producción interna. Ciertamente, los empresarios demandan también, pero su demanda no puede ser satisfecha mayoritariamente con producción local, por tanto, ella no constituye un factor dinamizante de la producción. Por consiguiente, se limita la posibilidad de generar nuevos empleos e ingresos y se agudizan las situaciones de miseria.

Por otro lado, como se observa en los datos que presentamos en los cuadros siguientes ${ }^{13}$, el excedente de explotación oscila en un rango que va desde el 34.3 por ciento en la construcción hasta el 85.2 por ciento en la refinería de petróleo, lo cual nos está mostrando dos formas de producir: la primera que usa de manera intensiva trabajadores o el factor trabajo, y la otra, que utiliza en forma intensiva la maquinaria o el factor capital. Se trata de dos tecnologías opuestas y de alguna manera determinadas por la naturaleza de la actividad. Ciertamente, no resulta posible reemplazar a las máquinas por trabajadores para refinar el crudo, pero sí es posible hacerlo en la construcción y de hecho se hace. Por ello es posible suponer que si las cosas marchan bien en la construcción, si esta actividad está muy dinámica, pues habrá un importante número de trabajadores que estarán percibiendo salarios y, en consecuencia, tendrán capa-

10. Ibid.

11. Ibid. Las cursivas son del autor.

12. CEPAL, Panorama Social de América Latina 1997, p. 31.

13. Los datos que presentamos en los cuadros corresponden tan sólo al 51.32 por ciento del valor agregado total. La totalidad de ramas y sectores puede consultarse en Matriz insumo-producto de 1990, Banco Central de Reserva. 
cidad de compra. Semejante a la refinería es el caso de la avicultura, ya que en esta rama de la agricultura el 82.8 por ciento del valor agregado está destinado a los empresarios y tan sólo un 3.4 por ciento, a los trabajadores.

\section{Cuadro 1 \\ Distribución del valor agregado en algunas actividades, ramas y sectores seleccionados, 1990 (en millones de colones)}

\begin{tabular}{|c|c|c|c|c|c|c|}
\hline & Total & Café & Caña & Ganadería & Avicultura & Electricidad \\
\hline Remuneraciones al trabajo & 11659.1 & 747.0 & 69.4 & 452.4 & 19.1 & 123.5 \\
\hline Impuesto ind. netos de subs. & 1612.1 & 264.0 & 0.0 & 4.3 & 70.3 & 1.1 \\
\hline Excedente bruto & 22570.5 & 645.9 & 153.1 & 672.2 & 460.0 & 178.7 \\
\hline \multirow[t]{2}{*}{ Valor agregado } & 35841.8 & 1656.9 & 222.5 & 1133.1 & 555.5 & 303.4 \\
\hline & $\begin{array}{l}\text { Construc- } \\
\text { ción }\end{array}$ & Comercio & $\begin{array}{l}\text { Rest. y } \\
\text { hoteles }\end{array}$ & $\begin{array}{l}\text { Transp. y } \\
\text { almacen. }\end{array}$ & $\begin{array}{l}\text { Comuni-. } \\
\text { caciones }\end{array}$ & $\begin{array}{c}\text { Bancos, } \\
\text { seguros, etc. }\end{array}$ \\
\hline Remuneraciones al trabajo & 787.5 & 1555.0 & 209.9 & 357.2 & 193.9 & 525.0 \\
\hline Impuesto ind. netos de subs. & 55.9 & 48.4 & 18.0 & 48.4 & 24.3 & 12.4 \\
\hline Excedente bruto & 440.5 & 3938.0 & 842.4 & 1532.8 & 526.9 & 307.6 \\
\hline Valor agregado & 1284.1 & 5542.3 & 1070.4 & 1938.5 & 745.2 & 845.0 \\
\hline \multicolumn{7}{|c|}{ Algunas ramas de la industria } \\
\hline & Bebidas & Textiles R & Refinería & Químicos & Cuero & Madera \\
\hline Remuneraciones al trabajo & 188.8 & 263.1 & 14.1 & 222.5 & 178.6 & 57.9 \\
\hline Impuesto ind. netos de subs. & 305.9 & 42.5 & 53.6 & 57.1 & 15.8 & 8.8 \\
\hline Excedente bruto & 349.5 & 327.8 & 388.1 & 381.5 & 201.7 & 42.1 \\
\hline Valor agregado & 844.3 & 633.5 & 455.8 & 661.2 & 396.2 & 108.8 \\
\hline
\end{tabular}

Fuente: Elaborado a partir de la Matriz insumo-producto de 1990, Banco Central de Reserva.

Otras ramas con elevada concentración del ingreso son: el comercio, las comunicaciones, los restaurantes y hoteles, así como el transporte y almacenamiento. La razón es muy sencilla: en sus actividades requieren de muy poca mano de obra en relación con la inversión de capital. Realidad opuesta presentan la agricultura y la industria, donde los casos de la refinería y la avicultura más que la regla son la excepción. En el caso del valor agregado, en la caficultura observamos que se distribuye mayoritariamente a favor del trabajo, en razón de que su cultivo y recolección demandan bastante fuerza de trabajo, no ocurre lo mismo con la caña donde la fase de cultivo está bastante mecanizada. La industria, al menos en las ramas presentadas, presenta una distribución mucho más ba- lanceada, así tenemos por ejemplo en el área de los textiles $\mathbf{4 1 . 5}$ por ciento para los trabajadores y 51.7 por ciento para los empresarios; mientras que en la industria del cuero se destinan 45.1 y 50.9 por ciento a los trabajadores y empresarios, respectivamente.

De manera general, pues, es posible establecer como posible factor explicativo del desempleo y de la pobreza existente a la terciarización de la economía, ocurrida en los últimos tiempos en el país, ya que estos sectores demandan poca fuerza de trabajo y/o pagan muy bajas remuneraciones a sus trabajadores, lo cual se refleja en la baja proporción que representan los salarios dentro del valor agregado en los sectores constitutivos del terciario: comercio y servicios (ver Cuadro 2). 
Si además consideramos que el sector terciario representa casi una tercera parte del valor agregado total y que sólo el sector comercio representa el
15.5 por ciento del mismo, lo que se ha mencionado adquiere más relevancia.

\section{Cuadro 2}

Estructura porcentual del valor agregado en algunas actividades, ramas y sectores seleccionados, 1990 (en millones de colones)

\begin{tabular}{|c|c|c|c|c|c|c|}
\hline & Total & Café & Caña & Ganadería & Avicultura & Electricidad \\
\hline Remuneraciones al trabajo & 32.5 & 45.1 & 31.2 & 39.9 & 3.4 & 40.7 \\
\hline Impuesto ind. netos de subs. & 4.5 & 15.9 & 0.0 & 0.4 & 12.7 & 0.4 \\
\hline Excedente bruto & 63.0 & 39.0 & 68.8 & 59.3 & 82.8 & 58.9 \\
\hline \multirow[t]{2}{*}{ Valor agregado } & 100.0 & 100.0 & 100.0 & 100.0 & 100.0 & 100.0 \\
\hline & \multicolumn{3}{|c|}{$\begin{array}{l}\text { Construc- Comercio Rest. y } \\
\text { ción }\end{array}$} & $\begin{array}{l}\text { Transp. y } \\
\text { almacen. }\end{array}$ & $\begin{array}{l}\text { Comuni- } \\
\text { caciones }\end{array}$ & $\begin{array}{l}\text { Bancos, } \\
\text { seguros, etc. }\end{array}$ \\
\hline Remuneraciones al trabajo & 61.3 & 28.1 & 19.6 & 18.4 & 26.1 & 62.1 \\
\hline Impuesto ind. netos de subs. & 4.4 & 0.8 & 1.7 & 2.5 & 3.2 & 1.5 \\
\hline Excedente bruto & 34.3 & 71.1 & 78.7 & 79.1 & 70.7 & 36.4 \\
\hline Valor agregado & 100.0 & 100.0 & 100.0 & 100.0 & 100.0 & 100.0 \\
\hline \multicolumn{7}{|c|}{ Algunas ramas de la industria } \\
\hline & Bebidas & Textiles & Refinería & Químicos & Cuero & Madera \\
\hline Remuneraciones al trabajo & 22.4 & 41.5 & 3.1 & 33.7 & 45.1 & 53.2 \\
\hline Impuesto ind. netos de subs. & 36.2 & 6.7 & 11.6 & 8.6 & 4.0 & 8.0 \\
\hline Excedente bruto & 41.4 & 51.7 & 85.2 & 57.7 & 50.9 & 38.7 \\
\hline Valor agregado & 100.0 & 100.0 & 100.0 & 100.0 & 100.0 & 100.0 \\
\hline
\end{tabular}

N.B. en algunos casos los porcentajes no suman 100 debido a que el valor agregado fue tomado directamente de la fuente y no sumado de los datos y éstos fueron aproximados al presentarlos en millones de colones.

Fuente: estimación propia a partir de cuadro anterior.

Deseamos dejar señalado que la distribución del valor agregado depende básicamente de dos factores: el primero es la tecnología, la cual determina la relación entre capital y trabajo, o lo que es lo mismo, entre máquinas y hombres que se presenta en el proceso de trabajo; y el segundo factor es el nivel de las remuneraciones, las cuales si son excesivamente bajas, por muchos que sean los trabajadores que se ocupen, siempre la proporción del valor agregado que se destine a los trabajadores será menor que aquella que se destina a los empresarios.
El factor tecnológico o la determinación tecnológica es compleja ya que depende de muchos elementos, los cuales podrían ser la naturaleza de la actividad, la posibilidad real de mecanizar un determinado proceso, el precio de los factores - capital y humano--, el desarrollo del mercado y la competencia, el desarrollo científico y las investigaciones tecnológicas, la incidencia extranjera en la importación de tecnología, etc. Pero, por otra parte, es importante destacar que entre las distintas posibles combinaciones de capital y trabajo existentes, la escogitación de la técnica más indicada 
la realiza el empresario capitalista, atendiendo a su lógica de maximización de ganancias.

El nivel de remuneración depende también de varios factores, como la relación entre oferta y demanda de empleo, la organización y lucha de los trabajadores, la visión de los empresarios, la existencia o no de regulaciones salariales, la tradición cultural, el nivel de formación de los trabajadores, etc.

Como se puede observar, la forma en que se determina la distribución del valor agregado entre trabajadores y empresarios es bastante compleja, de allí que si por razones de justicia distributiva o por razones estrictamente económicas se quisiera alterar la actual estructura concentrada del ingreso, afectando la composición del valor agregado, no se crea que ello es posible hacerlo por decreto o por mera voluntad. De hacerse, las consecuencias no se harían esperar inmediatamente, ya que cuando no se tiene en cuenta la realidad de las cosas,

sale peor el remedio que la enfermedad. Esto no significa que sea imposible alterar la concentración estructural del ingreso, no, lo que nos interesa destacar es que las medidas usualmente utilizadas no han sido las más indicadas y convenientes, como sería el caso en que a consecuencia de un intento redistributivo se terminara disminuyendo la masa de riqueza que se buscaba redistribuir.

\section{Cuadro 3}

Contribuyentes que declararon renta e impuestos computados, por personas naturales y jurídicas, valores absolutos y en porcentajes, 1997

(en miles de colones)

\begin{tabular}{l|c|c|c|c}
\hline Rangos & \multicolumn{2}{|c|}{ Número contribuyentes } & \multicolumn{2}{c}{ Impuesto computado } \\
\hline Personas naturales & Valor absoluto & $\%$ & Valor absoluto & $\%$ \\
\hline Menor a 0.00 & 39 & 0.11 & 660.9 & 0.39 \\
De 0.00 a 22000 & 392 & 1.12 & 1402.1 & 0.08 \\
De 22000 a 80 000 & 20728 & 59.43 & 62578.3 & 3.87 \\
De 80 000 a 200 000 & 7096 & 20.34 & 108314.4 & 6.40 \\
Arriba de 200 000 & 4118 & 11.81 & 422373.7 & 24.96 \\
Subtotal & 32373 & 92.82 & 595329.6 & 35.18 \\
Personas jurídicas & 2505 & 7.18 & 1096715.0 & 64.82 \\
\hline Total & 34878 & 100.00 & 1692044.7 & 100.00 \\
\hline
\end{tabular}

Fuente: Ministerio de Hacienda, DGII.

Una forma adicional para aproximamos a cuál es la distribución del ingreso es aquella que se puede inferir a partir de la información dada a conocer por el Ministerio de Hacienda, en lo que a contribuyentes e impuestos respecta, ya que en principio es posible suponer que cuanto más se gana más se tributa o se contribuye a las finanzas públicas. 
La información que se obtiene a partir del Cuadro 3 se corresponde aproximadamente con aquella presentada a partir de la Matriz insumo-producto, ya que si suponemos que las personas naturales se corresponden con los perceptores de salarios y las personas jurídicas con los empresarios, la magnitud del impuesto adjudicado a las personas jurídicas es casi el doble del asignado a las personas naturales, 64.82 y 35.18 por ciento, respectivamente. $Y$ resulta lógico pensar que la magnitud de los impuestos se corresponde con la magnitud de los ingresos que perciben las personas naturales y las empresas, aunque ello sea de manera aproximada.

Por otra parte, la información de Hacienda agrega a la obtenida de la Matriz, el hecho de pre- sentar número de contribuyentes: 32373 personas naturales y 2505 empresas, lo que en términos porcentuales podría considerarse quizá de manera muy aproximada como la estructura de distribución del ingreso, esto es, que al 92.82 por ciento de los contribuyentes, personas naturales, les corresponde el 35.68 por ciento del ingreso, mientras que al 7.18 por ciento de los contribuyentes, personas jurídicas, les corresponde el 64.82 por ciento del ingreso.

Claro que si el Ministerio de Hacienda divulgara toda la información que posee, se tendría una visión - acerca de la distribución del ingreso- bastante más cercana a la realidad respecto a la que presentamos en los Cuadro 3 y 4.

Cuadro 4

IVA pagado por cartera de contribuyentes, 1997 (en millones de colones)

\begin{tabular}{lcccc}
\hline & Contribuyentes & Porcentajes & Impuestos & Porcentajes \\
\hline Pequeños & 59503 & 91.97 & 555.24 & 18.98 \\
Medianos & 4336 & 6.68 & 489.26 & 16.72 \\
Grandes & 1070 & 1.65 & 1884.59 & 64.41 \\
\hline Total & 64909 & 100.00 & 2926.00 & 100.00 \\
\hline
\end{tabular}

Fuente: Ministerio de Hacienda, DGII.

En el Cuadro 4, en el cual se registra la captación del IVA - personas y empresas que venden productos y servicios y trasladan el impuesto al comprador-, también se insinúa una cierta estructura de distribución del ingreso, la cual se presenta muy concentrada: apenas el 1.65 por ciento de los "contribuyentes" capta el 64.41 por ciento del IVA. Se podría añadir que la estructura de distribución del ingreso anterior se corresponde más con la distribución del ingreso entre las empresas que entre las personas, con ello estaríamos diciendo que la distribución del ingreso en el interior del sector de las empresas se presenta concentrada en muy pocas manos.

Ahora bien, si existe cierta concentración en la tributación es porque existe acumulación en el ingreso, y esto obedece a que hay una concentración en la actividad económica y en la propiedad de las empresas que centralizan la actividad económica. $\mathrm{Y}$ es precisamente este tema el que abordaremos a continuación.

\section{La concentración de la actividad económica}

Con todo lo incompleta que es la información que presentamos en el Cuadro 5, por lo menos nos permite establecer la estructura de la actividad económica en el país. Y son dos hechos los que marcan esta actividad: la heterogeneidad estructural y la concentración estadístico-estructural (Cuadro 5). 
Cuadro 5

Visión general de las empresas por sector y tamaño

\begin{tabular}{lrrrrr}
\hline & Micro* & Pequeña & Mediana & Grande & Total \\
\hline Manufactura 1/ & 6314 & 946 & 556 & 66 & 7882 \\
Comercio por mayor 2/ & 1153 & 83 & 283 & 21 & 1540 \\
Comercio por menor 3/ & 71250 & 738 & 946 & 162 & 73096 \\
Servicios 4/ & 94812 & 1885 & 618 & 74 & 97389 \\
Exportaciones café 5/ & & 32 & 38 & 14 & 84 \\
Beneficios de café 6/ & & 5 & 51 & 34 & 93 \\
Ingenios azucareros 7/ & & 0 & 5 & 4 & 9 \\
Electricidad product. & & 2 & 0 & 1 & 3 \\
Electricidad distrib. 8/ & n.d. & 5 & 1 & 3 & 5 \\
Bancos 9/ & 178369 & 71675 & 28693 & 7446 & 286183 \\
Agricultura 10/ & n.d. & n.d. & n.d. & n.d. & n.d. \\
Construcción & n.d. & n.d. & n.d. & n.d. & n.d. \\
Transporte & 351898 & 75372 & 31198 & 7828 & 466296 \\
\hline Total & 75.47 & 16.16 & 6.69 & 1.69 & 100.00 \\
\hline Porcentajes & & & &
\end{tabular}

* Las microempresas son aquellas que tienen 4 y menos personas ocupadas, excepto en la agricultura.

1/ Pequeñas son aquellas empresas cuya producción bruta llega hasta 1 millón; medianas, las que su producción puede ser mayor de 1 millón hasta 50 millones; y grandes, las que sobrepasan los 50 millones.

2/ Pequeñas, cuando tienen 1 millón de ventas anuales; medianas, cuando tienen más de 1 millón hasta 50 millones, y grandes, más de 50 millones.

3/ Pequeñas, cuando tienen 1 millón de ventas anuales; medianas, las que tienen más de 1 millón hasta 10 millones, y grandes, cuando tienen más de 10 millones.

4// Pequeñas, si tienen 1 millón de ventas anuales; medianas si tienen más de 1 millón hasta 10 millones, y grandes cuando tienen más de 10 millones.

5/ Pequeñas, cuando tienen menos de 1 millón de dólares; medianas, entre 1 y 5 millones, y grandes, más de 5 millones de dólares.

6/ Pequeña, cuando el valor de producción bruta puede ser hasta de 1 millón de colones; medianas; más de 1 millón hasta 10 millones, y grandes, más de 10 millones.

$7 /$ Pequeñas cuando tienen hasta 199 ocupados; medianas si tienen de 200 hasta 299 , y grandes, cuando tienen 300 o más ocupados.

8/ Pequeñas cuando tienen hasta 50 personas ocupadas; medianas, si tienen más de 50 hasta 99, y grandes, de 100 y más personas ocupadas.

9/ Bancos pequeños si tienen hasta mil millones de depósitos; medianos si cuentan hasta con cinco mil millones, y grandes, cuando tienen más de cinco mil millones de colones en depósitos.

10/ Microempresas son las explotaciones menores de $2 \mathrm{mz}$; pequeñas, las que son mayores de $2 \mathrm{mz}$ pero menores de $10 \mathrm{mz}$; medianas, las que son de 10 pero menores de $50 \mathrm{mz}$, y grandes, las de 50 y más manzanas.

Fuente: Elaboración nuestra a partir de los cuadros que se citan más adelante.

La heterogeneidad estructural se manifiesta en el hecho de que más de las tres cuartas partes de las empresas son microempresas y se caracterizan por no operar conforme al denominado sector modemo, formal o capitalista de la economía, por tal razón se le denomina sector tradicional, informal o no capitalista. Sin embargo, la magnitud de la pro- ducción o la cantidad de valor agregado generado en el sector de las microempresas es insignificante en relación con el que producen las demás empresas en cada uno de los sectores.

Por otra parte tenemos la concentración estadístico-estructural, que se evidencia en el hecho de 
que un pequeño número de empresas controla un elevado porcentaje del valor agregado, como lo veremos a continuación en aquellos sectores de los cuales disponemos de información.

\subsection{La concentración en la industria manufac- turera}

La industria es una actividad típica en términos de concentración ya que, inclusive sin considerar a las microempresas, observamos que de un total de 1568 empresas, el 4.2 por ciento controla más de la mitad de las remuneraciones pagadas, de los activos fijos, cerca de las tres cuartas partes de la producción bruta y mucho más de la mitad del valor agregado.

\section{Cuadro 6}

Estructura de las empresas de la industria manufacturera con 5 y más personas ocupadas, según el Valor Bruto de la Producción (VBP), 1992

\begin{tabular}{lc|rc|rrrrr}
\hline & & \multicolumn{2}{|c|}{ Ocupados } & \multicolumn{4}{c}{ Valor en miles de colones } \\
\hline $\begin{array}{l}\text { Valor bruto } \\
\text { producción }\end{array}$ & $\begin{array}{l}\text { Núm. de } \\
\text { empresas }\end{array}$ & Total & $\begin{array}{c}\text { Remu- } \\
\text { nerados }\end{array}$ & $\begin{array}{l}\text { Remunerac. } \\
\text { pagadas 1/ }\end{array}$ & $\begin{array}{c}\text { Activo } \\
\text { fijo }\end{array}$ & \multicolumn{1}{c}{$\begin{array}{c}\text { Prod. } \\
\text { bruta }\end{array}$} & $\begin{array}{c}\text { Valor } \\
\text { agregado }\end{array}$ \\
\hline Pequeñas & 946 & 8244 & 6848 & 87708 & 126644 & 325941 & 166208 \\
Medianas & 556 & 45764 & 44887 & 936497 & 1525137 & 4830931 & 2350780 \\
Grandes 2/ & 66 & 26227 & 26158 & 1123554 & 3690019 & 14097977 & 5404489 \\
\hline Total & 1568 & 80235 & 77893 & 2147759 & 5637800 & 19254849 & 7921477 \\
\hline
\end{tabular}

1/: Comprende pagos al ISSS y otras remuneraciones. 2/: pequeñas son aquellas empresas cuya producción bruta llega hasta 1 millón; medianas, las de más de 1 millón hasta 50 millones, y grandes, las que sobrepasan los 50 millones.

Fuente: Elaborado a partir de la información de los Censos Económicos, Tomo 1, p. 77, DIGESTYC, 1992.

Las medianas empresas, que representan poco más de una tercera parte de las empresas, controlan más de la mitad de las personas ocupadas y remuneradas, pero tan sólo responde por un poco más de la cuarta parte de la producción bruta y el valor agregado.

\section{Cuadro 7}

Estructura porcentual de las empresas de la industria manufacturera con 5 y más personas ocupadas, según el Valor Bruto de la Producción (VBP), 1992

\begin{tabular}{lccccccc}
\hline VBP & $\begin{array}{c}\text { Núm. de } \\
\text { empresas } \\
\%\end{array}$ & $\begin{array}{c}\text { Total } \\
\text { ocupados } \\
\%\end{array}$ & $\begin{array}{c}\text { Remu- } \\
\text { nerados } \\
\%\end{array}$ & $\begin{array}{c}\text { Remunerac. } \\
\text { pagadas } \\
\%\end{array}$ & $\begin{array}{c}\text { Activo } \\
\text { fijo } \\
\%\end{array}$ & $\begin{array}{c}\text { Prod. } \\
\text { bruta } \\
\%\end{array}$ & $\begin{array}{c}\text { Valor } \\
\text { agregado } \\
\%\end{array}$ \\
\hline Pequeñas & 60.33 & 10.27 & 8.79 & 4.08 & 2.41 & 1.69 & 2.10 \\
Medianas & 35.46 & 57.04 & 57.62 & 43.60 & 28.57 & 25.09 & 29.68 \\
Grandes & 4.21 & 32.69 & 33.58 & 53.31 & 69.23 & 73.22 & 68.23 \\
\hline Total & 100.00 & 100.00 & 100.00 & 100.00 & 100.00 & 100.00 & 100.00 \\
\hline
\end{tabular}

Fuente: Estimación propia a partir de la información citada. 


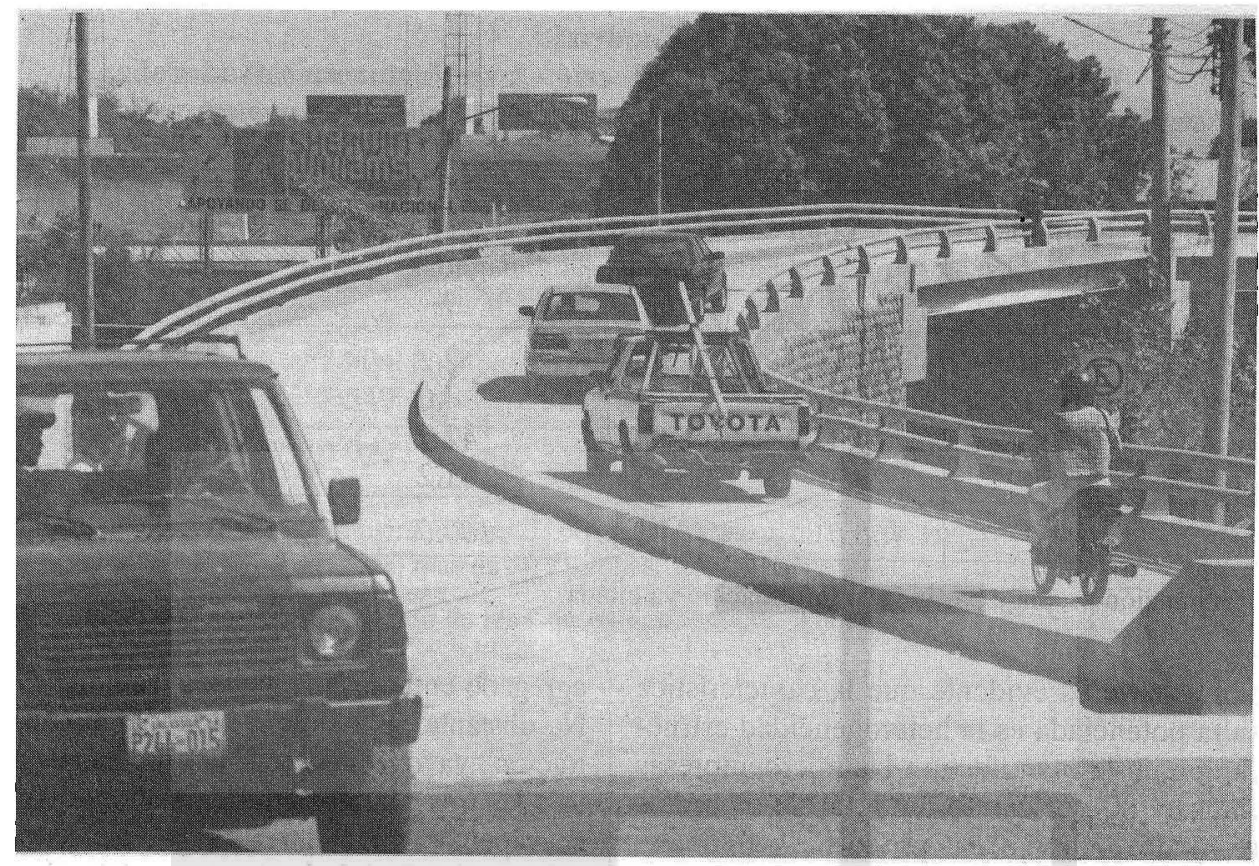

En el Cuadro 7 podemos observar que las pequeñas empresas, que conforman casi las dos terceras partes del sector, ocupan sólo a un 10 por ciento y están por debajo del 5 por ciento respecto a remuneraciones, activos fijos, producción bruta y valor agregado.

Por otra parte, la gran empresa aun teniendo un porcentaje menor de remunerados que la mediana empresa, tiene un mayor porcentaje en cuanto a remuneraciones pagadas, lo cual nos indica que la gran empresa paga mayores salarios y adicionalmente posee niveles de productividad más altos, como se observa al relacionar el valor agregado de cada categoría entre el número respectivo de trabajadores remunerados.

\section{Cuadro 8}

Estructura de la producción manufacturera salvadoreña según el tamaño de la empresa: micro, pequeña, mediana y gran empresa, 1992

\begin{tabular}{lc|rr|rrr}
\hline & & Ocupados & \multicolumn{3}{c}{ Valor en miles de colones } \\
\hline $\begin{array}{l}\text { Valor Bruto } \\
\text { Producción }\end{array}$ & $\begin{array}{l}\text { Núm. de } \\
\text { empresas }\end{array}$ & Total & $\begin{array}{c}\text { Remu- } \\
\text { nerados }\end{array}$ & $\begin{array}{c}\text { Remunerac. } \\
\text { pagadas }\end{array}$ & $\begin{array}{c}\text { Prod. } \\
\text { bruta }\end{array}$ & $\begin{array}{c}\text { Valor } \\
\text { agregado }\end{array}$ \\
\hline Micro 1/ & 6314 & 12443 & 4707 & 47741 & 349479 & 179787 \\
Pequeñas & 946 & 8244 & 6848 & 87708 & 325941 & 166208 \\
Medianas & 556 & 45764 & 44887 & 936497 & 4830931 & 2350780 \\
Grandes & 66 & 26227 & 26158 & 1123554 & 14097977 & 5404489 \\
\hline Total & 7882 & 92678 & 82600 & 2195500 & 19604328 & 8101264 \\
\hline
\end{tabular}

1/: Las microempresas son aquellas que tienen 4 y menos personas ocupadas; el criterio para clasificar las pequeñas, medianas y grandes es el mismo que ya se comentó.

Fuente: Elaborado a partir de información de los Censos Económicos, Tomos I y II, DIGESTYC, 1992.

Cuando incluimos dentro del estudio de la concentración en el sector manufacturero a las microempresas, se nos presentan variaciones significati- vas en tan sólo dos rubros: en el número de empresas y el en número de ocupados, como se observa en el Cuadro 8. 


\section{Cuadro 9}

Estructura porcentual de la producción manufacturera salvadoreña, según el tamaño de la empresa: micro, pequeña, mediana y gran empresa, 1992

\begin{tabular}{|c|c|c|c|c|c|c|}
\hline \multirow[b]{2}{*}{$\begin{array}{l}\text { Valor Bruto } \\
\text { Producción }\end{array}$} & \multirow[b]{2}{*}{$\begin{array}{c}\text { Núm. de } \\
\text { empresas } \\
\%\end{array}$} & \multicolumn{2}{|c|}{ Ocupados } & \multirow[b]{2}{*}{$\begin{array}{c}\text { Remunerac. } \\
\text { pagadas } \\
\%\end{array}$} & \multirow[b]{2}{*}{$\begin{array}{c}\text { Prod: } \\
\text { bruta } \\
\%\end{array}$} & \multirow[b]{2}{*}{$\begin{array}{c}\text { Valor } \\
\text { agregado } \\
\%\end{array}$} \\
\hline & & $\begin{array}{l}\text { Total } \\
\%\end{array}$ & $\begin{array}{c}\text { Remu- } \\
\text { nerados } \\
\%\end{array}$ & & & \\
\hline $\begin{array}{l}\text { Micro } \\
\text { Pequeñas } \\
\text { Medianas } \\
\text { Grandes }\end{array}$ & $\begin{array}{r}80.1 \\
12.0 \\
7.0 \\
0.8\end{array}$ & $\begin{array}{r}13.4 \\
8.9 \\
49.3 \\
28.3\end{array}$ & $\begin{array}{r}5.7 \\
8.3 \\
54.3 \\
31.7 \\
\end{array}$ & $\begin{array}{r}2.2 \\
4.0 \\
42.7 \\
51.2\end{array}$ & $\begin{array}{r}1.8 \\
1.7 \\
24.6 \\
71.9\end{array}$ & $\begin{array}{r}2.2 \\
2.1 \\
29.0 \\
66.7\end{array}$ \\
\hline Total & 100.0 & 100.0 & 100.0 & 100.0 & 100.0 & 100.0 \\
\hline
\end{tabular}

Fuente: Estimación propia a partir de la información ya citada.

Por otra parte es evidente que la característica que resulta potenciada es la heterogeneidad estructural, ya que en la manufactura las microempresas representan el 80 por ciento del total de empresas del sector; sin embargo, su producción bruta no llega al 1.8 por ciento y el valor agregado apenas supera el 2 por ciento. Lo que resulta destacable es que menos del 1.0 por ciento de las empresas manufactureras controlan el 71.9 y 66.7 por ciento de la producción bruta y el valor agregado, respectivamente, lo cual nos indica la elevada concentración estadístico-estructural existente en el sector. $Y$ si consideramos que las remuneraciones en la gran empresa apenas representan el 15.59 por ciento del valor agregado respectivo, es obvio que también existe concentración del ingreso.

\subsection{La concentración en el sector comercio}

Al igual que lo hicimos con la manufactura, el estudio del sector comercio también lo haremos excluyendo en un primer momento a la microempresa, luego procederemos a estudiar el comercio al por mayor y al por menor en empresas de cinco y más personas ocupadas. El sector comercio admite estas dos grandes divisiones, de allí que hasta haber concluido esta parte incluiremos a las microempresas tanto en el comercio al por mayor como al por menor.

\subsubsection{El comercio al por mayor}

Al considerar la información sobre el comercio al por mayor, llama la atención el pequeño número de empresas existentes en el subsector y la poca diferencia que existe en término de ingresos y valor agregado entre las medianas y las grandes empresas. No obstante, se mantiene el fenómeno de la concentración, ya que mientras las medianas representan casi las tres cuartas partes de las empresas, las grandes apenas suman un 5.43 por ciento y controlan más de la mitad de las ventas y del valor agregado; sin embargo, las empresas medianas controlan dos tercios de los ocupados, de los remunerados y de las remuneraciones, mientras que las grandes no llegan a controlar ni la cuarta parte de los ocupados y los remunerados, a excepción de las remuneraciones pagadas que alcanzan una tercera parte del total.

La relación entre remuneraciones y valor agregado en las empresas medianas es de 33.3 por ciento y en las grandes apenas alcanza el 15.6 por ciento, con ello se evidencia, una vez más, la elevada concentración del ingreso que existe en nuestra economía. A nivel del subsector, el comercio al por mayor presenta una relación remuneraciones/valor agregado del 24.20 por ciento, mientras que en la manufactura es del 25.42 por ciento, es decir, ligeramente superior. Este fenómeno es así en el comercio debido a la poca contratación de trabajadores y/o a las bajas remuneraciones de los mismos que presenta el sector. Veamos si tal hipótesis se confirma o rechaza con la información obtenida.

Los datos nos indican que mientras en la industria existe 51.17 ocupados por empresa con una media salarial de 2297.76 colones mensuales, en el comercio al por mayor el promedio de ocupados por empresa es de 28.2 y la media salarial mensual es de 2927.52 colones. De donde la variable explicativa sería más que las remuneraciones, el bajo número de ocupados por empresa. 


\section{Cuadro 10}

Estructura de las empresas del sector comercio al por mayor con 5 y más personas ocupadas, según el valor de las ventas, 1992

\begin{tabular}{lc|cc|ccc}
\hline & & \multicolumn{2}{|c|}{ Ocupados } & \multicolumn{3}{c}{ Valor en miles de colones } \\
\hline $\begin{array}{l}\text { Valor de la } \\
\text { venta }\end{array}$ & $\begin{array}{l}\text { Núm. de } \\
\text { empresas }\end{array}$ & Total & $\begin{array}{l}\text { Remu- } \\
\text { nerados }\end{array}$ & $\begin{array}{r}\text { Remunerac. } \\
\text { pagadas 1/ }\end{array}$ & $\begin{array}{l}\text { Ventas e } \\
\text { ingresos }\end{array}$ & $\begin{array}{c}\text { Valor } \\
\text { agregado }\end{array}$ \\
\hline Pequeñas & 83 & 868 & 728 & 17909 & 88031 & 60576 \\
Medianas & 283 & 7504 & 7104 & 227652 & 2479984 & 684454 \\
Grandes 2/ & 21 & 2549 & 2522 & 118178 & 3370882 & 758052 \\
\hline Total & 387 & 10921 & 10354 & 363739 & 5938897 & 758052 \\
\hline
\end{tabular}

1/: incluye pagos al ISSS y otras remuneraciones. 2/: pequeñas, hasta 1 millón de ventas anuales; medianas, más de 1 millón hasta 50 millones, y grandes, más de 50 millones.

Fuente: Elaborado a partir de la información de los Censos Económicos, Tomo III, p. 84, DIGESTYC, 1992.

\section{Cuadro 11}

Estructura porcentual de las empresas del sector comercio al por mayor con 5 y más personas ocupadas, según el valor de las ventas, 1992

\begin{tabular}{ll|rr|rrr}
\hline & & \multicolumn{2}{|c|}{ Ocupados } & & & \\
\hline $\begin{array}{l}\text { Valor de la } \\
\text { venta }\end{array}$ & $\begin{array}{l}\text { Núm. de } \\
\text { empresas }\end{array}$ & \multicolumn{1}{|c|}{ Total } & $\begin{array}{c}\text { Remu- } \\
\text { nerados }\end{array}$ & $\begin{array}{c}\text { Remunerac. } \\
\text { pagadas }\end{array}$ & $\begin{array}{c}\text { Ventas e } \\
\text { ingresos }\end{array}$ & $\begin{array}{c}\text { Valor } \\
\text { agregado }\end{array}$ \\
\hline Pequeñas & 21.45 & 7.95 & 7.03 & 4.92 & 1.48 & 4.03 \\
Medianas & 73.13 & 68.71 & 68.61 & 62.59 & 41.76 & 45.54 \\
Grandes & 5.43 & 23.34 & 24.36 & 32.49 & 56.76 & 50.43 \\
\hline Total & 100.0 & 100.0 & 100.0 & 100.0 & 100.0 & 100.0 \\
\hline
\end{tabular}

Fuente: Elaboración propia sobre la base de información ya citada.

\subsubsection{El comercio al por menor}

Cuando se trata del comercio al por menor, la hipótesis de la poca ocupación y el bajo nivel salarial como factores explicativos de la baja relación remuneraciones/valor agregado se confirma, ya que encontramos un salario mensual promedio de 2024.50 colones, así como sólo 15.27 ocupados en promedio por empresa - ambas cifras están por debajo de las que presenta la manufactura y el comercio al por mayor-y una relación remuneracio- nes/valor agregado del 25.42 por ciento. Relación que baja hasta un 20.1 por ciento en el caso de las grandes empresas, lo cual refleja nuevamente una elevada concentración del ingreso. Si bien el número de empresas dedicadas al comercio al por menor casi quintuplica a las del comercio al por mayor, no ocurre lo mismo con las personas ocupadas que son casi triplicadas, que ni las ventas ni el valor agregado alcanzan siquiera a duplicarse. 


\section{Cuadro 12}

Estructura de las empresas del sector comercio al por menor con más de 5 personas ocupadas, según el valor de las ventas, 1992

\begin{tabular}{lc|rc|rrr}
\hline & & \multicolumn{2}{|c|}{ Ocupados } & \multicolumn{3}{c}{ Valor en miles de colones } \\
\hline $\begin{array}{l}\text { Ventas e } \\
\text { ingresos }\end{array}$ & $\begin{array}{l}\text { Núm. de } \\
\text { empresas }\end{array}$ & Total & $\begin{array}{c}\text { Remu- } \\
\text { nerados }\end{array}$ & $\begin{array}{l}\text { Remunerac. } \\
\text { pagadas } 1 /\end{array}$ & $\begin{array}{c}\text { Ventas e } \\
\text { ingresos }\end{array}$ & $\begin{array}{c}\text { Valor } \\
\text { agregado }\end{array}$ \\
\hline Pequeñas & 738 & 5167 & 3893 & 56914 & 373970 & 132449 \\
Medianas & 946 & 12689 & 11710 & 268210 & 3060322 & 833673 \\
Grandes 2/ & 162 & 10335 & 10129 & 300014 & 4994283 & 1492415 \\
\hline Total & 1846 & 28191 & 25732 & 625138 & 8428575 & 2458537 \\
\hline
\end{tabular}

1/: incluye pagos al ISSS y otras remuneraciones. 2/: pequeñas, hasta 1 millón de ventas anuales; medianas, más de 1 millón hasta 10 millones, y grandes, más de 10 millones.

Fuente: Elaborado a partir de la información de los Censos Económicos, Tomo III, p. 87, DIGESTYC, 1992.

En lo que a la concentración respecta, en este subsector observamos que las grandes empresas con un 8.78 por ciento del total controlan más de la mitad del total de las ventas e ingresos, pero tan sólo un poco más del tercio de las personas ocupadas, como se evidencia en el Cuadro 13.

Las empresas medianas sin ser tan importantes en número, como en el comercio al por mayor, con poco más de la mitad del total controlan cerca de la mitad del total de ocupados y alrededor también de la mitad de los remunerados $-45.01 \mathrm{y}$ 45.50 por ciento, respectivamente-, así como dos quintas partes de las remuneraciones pagadas y del valor agregado, esto es, 42.9 y 39.91 por ciento, respectivamente (Cuadro 13).

El comercio al por menor parece ser una de las actividades que genera mayor empleo; sin embargo, esto no es así cuando se trata del sector formal o capitalista de la economía, el cual llega a ocupar a 28121 personas, mientras que la manufactura ocupa a más de 80000 personas.

Al considerar tanto el comercio al por mayor como al por menor, la cifra de ocupados en el sector se incrementa a 39112 , la cual es todavía menor de la mitad de la que ocupa la industria con 5 y más personas ocupadas, esto es, el segmento industrial capitalista.

\section{Cuadro 13}

Estructura porcentual de las empresas del sector comercio al por menor con 5 y más personas ocupadas, según el valor de las ventas, 1992

\begin{tabular}{ll|cc|ccc}
\hline & & \multicolumn{2}{|c|}{ Ocupados } & & & \\
\hline $\begin{array}{l}\text { Ventas e } \\
\text { ingresos }\end{array}$ & $\begin{array}{l}\text { Núm. de } \\
\text { empresas }\end{array}$ & Total & $\begin{array}{l}\text { Remu- } \\
\text { nerados }\end{array}$ & $\begin{array}{c}\text { Remunerac. } \\
\text { pagadas }\end{array}$ & $\begin{array}{c}\text { Ventas e } \\
\text { ingresos }\end{array}$ & $\begin{array}{c}\text { Valor } \\
\text { agregado }\end{array}$ \\
\hline Pequeñas & 39.98 & 18.33 & 15.13 & 9.10 & 4.44 & 5.39 \\
Medianas & 51.24 & 45.01 & 45.50 & 42.90 & 36.31 & 39.91 \\
Grandes & 8.78 & 36.66 & 39.37 & 48.0 & 59.25 & 54.7 \\
\hline Total & 100.0 & 100.0 & 100.0 & 100.0 & 100.0 & 100.0 \\
\hline
\end{tabular}

Fuente: Elaboración propia a partir de información ya citada. 
4.2.3. El comercio al por mayor, incluyendo a la microempresa

Como se observa en los cuadros siguientes - Cuadros 14 y 15 -, el comercio al por mayor realizado por microempresas, como es lógico, re- sulta poco significativo, tanto en términos absolutos como relativos. Si bien el número de microempresas es bastante elevado, no lo es así el número de personas a las cuales ocupan, como tampoco las ventas que realizan y los ingresos que obtienen.

\section{Cuadro 14}

Estructura de las empresas del sector comercio al por mayor, según el tamaño de la empresa: micro, pequeña, mediana y gran empresa, 1992

\begin{tabular}{lc|rr|rrr}
\hline & & \multicolumn{2}{|c|}{ Ocupados } & & & \\
\hline $\begin{array}{l}\text { Tamaño de la } \\
\text { empresa }\end{array}$ & $\begin{array}{l}\text { Núm. de } \\
\text { empresas }\end{array}$ & Total & $\begin{array}{c}\text { Remu- } \\
\text { nerados }\end{array}$ & $\begin{array}{l}\text { Remunerac. } \\
\text { pagadas } 1 /\end{array}$ & $\begin{array}{r}\text { Ventas e } \\
\text { ingresos }\end{array}$ & $\begin{array}{c}\text { Valor } \\
\text { agregado }\end{array}$ \\
\hline Micro 2/ & 1153 & 2550 & 1013 & 17846 & 594756 & n.d. \\
Pequeñas & 83 & 868 & 728 & 17909 & 88031 & 60576 \\
Medianas & 283 & 7504 & 7104 & 227652 & 2479984 & 684454 \\
Grandes & 21 & 2549 & 2522 & 118178 & 3370882 & 758052 \\
\hline Total & 1540 & 13427 & 11367 & 381585 & 6533653 & 1503082 \\
\hline
\end{tabular}

1/: incluye pagos al ISSS y otras remuneraciones. 2/: son empresas con 4 y menos personas ocupadas.

Fuente: Elaborado a partir de información de los Censos Económicos, Tomo III, pp. 84 y 585, DIGESTYC, 1992.

El nivel de concentración se incrementa al incluir a las microempresas en el estudio, ya que las grandes empresas con apenas 1.36 por ciento del total controlan el 51.59 por ciento de las ventas, lo cual también parece ser normal tratándose del comercio al por mayor. Esto es lo que nos muestra el Cuadro 15.

\section{Cuadro 15}

Estructura porcentual de las empresas del sector comercio al por mayor, según el tamaño de la empresa: micro, pequeña, mediana y gran empresas, 1992

\begin{tabular}{ll|rc|ccc}
\hline & & \multicolumn{2}{|c|}{ Ocupados } & & & \\
\hline $\begin{array}{l}\text { Tamaño de las } \\
\text { empresas }\end{array}$ & $\begin{array}{l}\text { Núm. de } \\
\text { empresas }\end{array}$ & Total & $\begin{array}{r}\text { Remu- } \\
\text { nerados }\end{array}$ & $\begin{array}{c}\text { Remunerac. } \\
\text { pagadas }\end{array}$ & $\begin{array}{c}\text { Ventas e } \\
\text { ingresos }\end{array}$ & $\begin{array}{c}\text { Valor } \\
\text { agregado }\end{array}$ \\
\hline Micro & 74.87 & 19.0 & 8.91 & 4.68 & 9.10 & \\
Pequeñas & 5.39 & 6.46 & 6.40 & 4.69 & 1.35 & \\
Medianas & 18.38 & 55.89 & 62.50 & 59.66 & 37.96 & \\
Grandes & 1.36 & 18.99 & 22.19 & 30.97 & 51.59 & 100.0 \\
\hline Total & 100.0 & 100.0 & 100.0 & 100.0 & 100.0 & 100 \\
\hline
\end{tabular}

Fuente: elaboración propia a partir de información ya citada.

En el extremo opuesto se encuentran las mi- $\mid$ total de empresas que apenas controlan el 9.10 por croempresas que representan el 74.87 por ciento del $\mid$ ciento de las ventas e ingresos ${ }^{14}$. Y ya que consti-

14. Los datos sobre el valor agregado para las microempresas no son reportados por los Censos Económicos. 
tuyen un elevado número de empresas, pues, no resulta extraño que controlen más ocupados, más remunerados y más ventas e ingresos que las pequeñas empresas, como se puede evidenciar en el Cuadro 14.

En este subsector del comercio, "las estrellas" casi lo son las empresas medianas, ya que a pesar de representar tan sólo el 18 por ciento de las empresas dan ocupación al 56 por ciento de los empleados, tienen el 62 por ciento de los remunerados y pagan el 60 por ciento del total de remuneraciones. Es una lástima que no sean muy eficientes y que todos los datos anteriores no se correspondan con el nivel de ventas e ingresos, puesto que en este rubro las medianas empresas tan sólo responden por el 37.96 por ciento, cifra que está muy por debajo de las grandes empresas que ocupan menos personas y pagan porcentualmente menores remuneraciones.

\subsubsection{El comercio al por menor, incluyendo a las microempresas}

Lo que siempre se piensa del comercio en términos de ocupación, e inclusive de subocupación, se confirma cuando estudiamos el comercio al por menor incluyendo a las microempresas, ya que entonces se suman a los ocupados en el sector comercio: 100421 personas, como se puede ver en el Cuadro 16.

\section{Cuadro 16}

Estructura de las empresas del sector comercio al por menor, según el tamaño de la empresa: micro, pequeña, mediana y gran empresa, 1992

\begin{tabular}{lc|rr|rrr}
\hline & & \multicolumn{2}{|c|}{ Ocupados } & \multicolumn{3}{c}{ Valor en miles de colones } \\
\hline $\begin{array}{l}\text { Ventas e } \\
\text { ingresos }\end{array}$ & $\begin{array}{l}\text { Núm. de } \\
\text { empresas }\end{array}$ & \multicolumn{1}{|c|}{ Total } & $\begin{array}{c}\text { Remu- } \\
\text { nerados }\end{array}$ & $\begin{array}{l}\text { Remunerac. } \\
\text { pagadas 1/ }\end{array}$ & $\begin{array}{c}\text { Ventas e } \\
\text { ingresos }\end{array}$ & $\begin{array}{c}\text { Valor } \\
\text { agregado }\end{array}$ \\
\hline Micro 2/ & 71250 & 100421 & 17523 & 250970 & 8438200 & \\
Pequeñas & 738 & 5167 & 3893 & 56914 & 373970 & 132449 \\
Medianas & 946 & 12689 & 11710 & 268210 & 3060322 & 833673 \\
Grandes & 162 & 10335 & 10129 & 300014 & 4994283 & 1492415 \\
\hline Total & 73096 & 128612 & 43255 & 625138 & 16866775 & 2458537 \\
\hline
\end{tabular}

1/: incluye pagos al ISSS y otras remuneraciones. 2/: son empresas con 4 y menos personas ocupadas.

Fuente: Elaborado a partir de información de los Censos Económicos, Tomo IIl, pp. 87 y 585, DIGESTYC, 1992.

Sin embargo, la proporción de remunerados es ínfima en relación con el total de ocupados en las microempresas, ya que apenas representan un 17.4 por ciento. Ahora bien, como un hecho insólito, en este subsector del comercio al por menor la microempresa supera no sólo a las pequeñas y medianas empresas, en cuanto a ventas e ingresos, sino inclusive a la gran empresa. Las microempresas, que representan el 97.47 por ciento del total de empresas dedicadas al comercio al por menor, son responsables de la mitad del total de ventas e ingresos del subsector.

Por otra parte, las microempresas controlan el
78.08 por ciento de las personas ocupadas en el subsector y el 40.51 del personal remunerado, con lo cual superan a las grandes empresas. No obstante y pese a superar a las medianas y grandes empresas en cuanto al número de personas remuneradas -40.51 por ciento la microempresa versus 27.07 y 23.42 por ciento, de la mediana y gran empresas, respectivamente-, las microempresas son superadas en términos de remuneraciones pagadas, esto es, 40.15 por ciento de la microempresa versus 42.90 y 48.0 por ciento de la mediana y grande empresas, respectivamente (Cuadro 17). 


\section{Cuadro 17}

Estructura porcentual de las empresas del sector comercio al por menor, según el tamaño de la empresa: micro, pequeña, mediana y gran empresa, 1992

\begin{tabular}{ll|cc|ccc}
\hline & \multicolumn{2}{|c|}{ Ocupados } & & & \\
\hline $\begin{array}{l}\text { Tamaño de las } \\
\text { empresas }\end{array}$ & $\begin{array}{l}\text { Núm. de } \\
\text { empresas }\end{array}$ & Total & $\begin{array}{c}\text { Remu- } \\
\text { nerados }\end{array}$ & $\begin{array}{c}\text { Remunerac. } \\
\text { pagadas }\end{array}$ & $\begin{array}{c}\text { Ventas e } \\
\text { ingresos }\end{array}$ & $\begin{array}{c}\text { Valor } \\
\text { agregado }\end{array}$ \\
\hline Micro & 97.47 & 78.08 & 40.51 & 40.15 & 50.03 & \\
Pequeñas & 1.01 & 3.03 & 9.00 & 9.10 & 2.22 & \\
Medianas & 1.29 & 9.10 & 27.07 & 42.90 & 18.14 & \\
Grandes & 0.22 & 7.87 & 23.42 & 48.00 & 29.61 & 100.0 \\
\hline Total & 100.0 & 100.0 & 100.0 & 100.0 & 100.0 & 100 \\
\hline
\end{tabular}

Fuente: elaboración propia a partir de información ya citada.

Luego de estudiar el subsector del comercio al por menor y observar las cifras porcentuales que presenta el cuadro anterior es posible afirmar que, a diferencia del resto de sectores estudiados, en el comercio al por menor no existe concentración. A menos que consideremos concentración el hecho de que el 1 por ciento del total de empresas controle una tercera parte de las ventas e ingresos, como es el caso de las grandes empresas. Pero las microempresas controlan el 50.03 por ciento de las ventas e ingresos y emplean al 78 por ciento de los ocupados y al 40.51 por ciento de los remunerados.

El comercio mercantil no capitalista es una muestra fehaciente de que las formas no capitalistas de la economía perviven con las capitalistas, siempre y cuando el capital pueda servirse de las mismas para su funcionamiento. Y eso es precisamente lo que ocurre con el comercio no capitalis$\mathrm{ta}^{15}$. Adicionalmente podría sostenerse, a partir de lo anterior, que la competencia es más propia de la economía mercantil no capitalista que de la capitalista.

\subsection{La concentración en el sector servicios, restaurantes y hoteles}

Seguramente que, antes de ocuparnos del sector, es conveniente referimos primero a qué actividades se incluyen dentro del rubro servicios, ya que ello no parece ser tan claro u obvio como cuando nos ocupamos del comercio o de la manufactura, o de los restaurantes y hoteles. Por tanto, entre los servicios encontramos establecimientos financieros como bancos, financieras, compañías de seguros, cooperativas de ahorro y crédito, tarjetas de crédito, casas de cambio, bolsa de valores, montepíos, etc. Bienes inmuebles, lotificaciones,

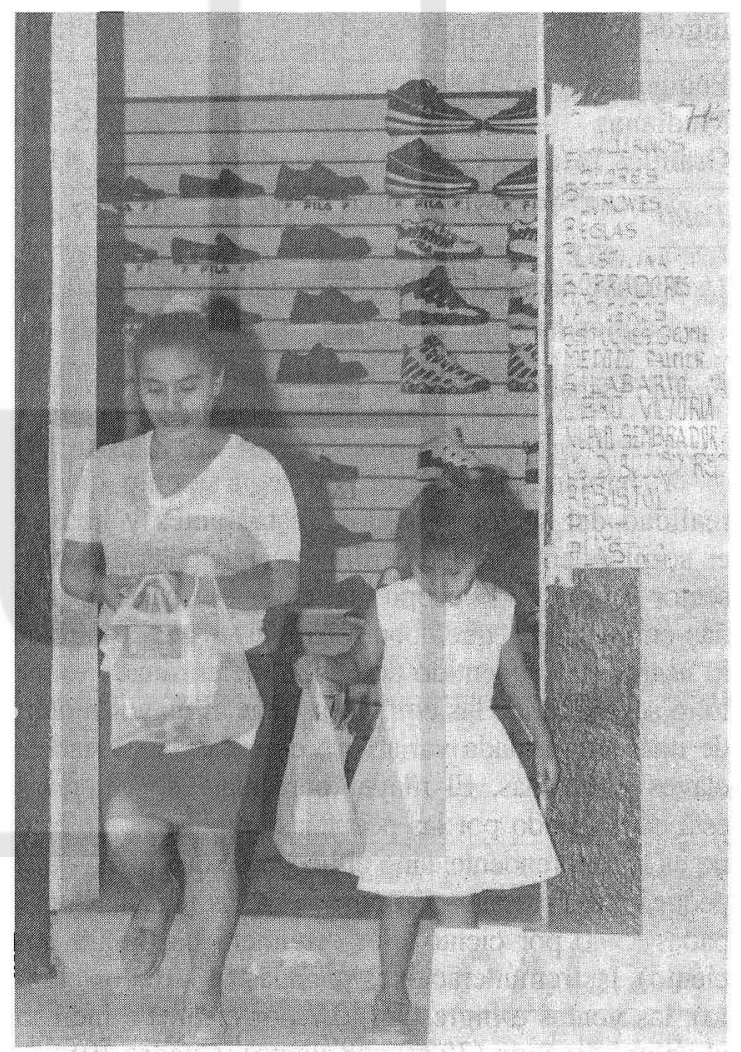

15. Para una explicación teórica al respecto, consulte A. Montoya, Economía Crítica, Cap. 8, San Salvador: Editores Críticos, 1998. 
venta y alquiler de viviendas, etc. Servicios jurídicos, contables, secretariales, técnicos y arquitectónicos, de publicidad, alquiler y arrendamiento de maquinaria y equipo, educativos como universidades, colegios, etc. Servicios médicos y odontológicos, veterinaria, etc. Medios de comunicación, servicios de diversión y esparcimiento, etc. Talleres de reparación, lavanderías, etc. Como se puede observar no sólo es un ámbito bastante amplio, sino bastante diverso en sus contenidos.

También es importante señalar que, tal como se hizo con los otros sectores, analizaremos primero al sector sin considerar a las microempresas, es decir con la finalidad de tener una percepción sólo del ámbito capitalista de la economía. Posteriormente consideraremos a las microempresas para tener una visión global del sector. Tratamos de detectar si en éste existe concentración estadísticoestructural, ya que ése es el objetivo principal de la investigación, sin descuidar otros aspectos relevantes que pudieran aparecer y que no estaban considerados. Ciertamente, sin llegar al punto de divagar con cualquier problemática que se nos presente, no abandonamos nuestra concepción investigativa al considerar a "la investigación como una aventura de la razón" y, en este sentido, estar abiertos a las sorpresas que nos brinda la realidad.

\section{Cuadro 18}

Estructura de las empresas del sector servicios, restaurantes y hoteles con 5 y más personas ocupadas, según el valor de las ventas, 1992

\begin{tabular}{ll|rr|ccc}
\hline & & \multicolumn{2}{|c|}{ Ocupados } & \multicolumn{3}{c}{ Valor en miles de colones } \\
\hline $\begin{array}{l}\text { Ventas e } \\
\text { ingresos }\end{array}$ & $\begin{array}{l}\text { Núm. de } \\
\text { empresas }\end{array}$ & Total & $\begin{array}{l}\text { Remu- } \\
\text { nerados }\end{array}$ & $\begin{array}{c}\text { Remunerac. } \\
\text { pagadas } 1 /\end{array}$ & $\begin{array}{c}\text { Ventas e } \\
\text { ingresos }\end{array}$ & $\begin{array}{c}\text { Valor } \\
\text { agregado }\end{array}$ \\
\hline Pequeñas & 1885 & 30722 & 27568 & 578918 & 2324288 & 1805535 \\
Medianas & 618 & 16902 & 15744 & 454742 & 2059346 & 1615032 \\
Grandes 2/ & 74 & 4268 & 4153 & 149893 & 1327537 & 1128679 \\
\hline Total & 2577 & 51892 & 47465 & 1183553 & 5711171 & 4549246 \\
\hline
\end{tabular}

1/: incluye pagos al ISSS y otras remuneraciones. 2/: pequeñas, hasta 1 millón de ventas anuales; medianas, más de 1 millón hasta 10 millones, y grandes, más de 10 millones.

Fuente: Elaborado a partir de información de los Censos Económicos, Tomo III, p. 256, DIGESTYC, 1992.

Y hablando de sorpresas, seguramente que la realidad del sector servicios, restaurantes y hoteles es sorprendente ya que, a diferencia de cualquier otro sector formal de la economía, en éste son las pequeñas empresas las que "controlan" el sector. Controlar lo usamos en el sentido de que un determinado estrato, o segmento de las empresas, tiene el mayor monto de una determinada variable o de todas las variables claves estudiadas. El mayor porcentaje de empresas está conformado por las pequeñas empresas pero esto no es lo sorprendente, sino el hecho de que éstas - las pequeñas empresas - "controlen" a las personas ocupadas (59.0 por ciento), los remunerados (58.08 por ciento), las remuneraciones pagadas (48.91 por ciento), las ventas e ingresos (40.7 por ciento) e incluso el valor agregado (39.69 por ciento) (Cuadro 19).
Ciertamente, el subsector de las pequeñas empresas refleja algún grado de ineficiencia, en tanto que la relación que guardan las variables de ocupados y remuneraciones con las ventas y el valor agregado es desproporcionada y tiende hacia la baja, como lo muestran los datos respectivos siguientes: el 59.2 por ciento para los ocupados y el 48.91 por ciento para las remuneraciones versus el 40.7 por ciento en ventas y 39.69 por ciento de valor agregado. Todo lo contrario ocurre con las grandes empresas, donde observamos para los ocupados y las remuneraciones el 2.87 y 12.66 por ciento, respectivamente, versus las ventas y el valor agregado con un 23.24 y 24.8 por ciento, respectivamente. 
Cuadro 19

Estructura porcentual de las empresas del sector servicios, restaurantes y hoteles con 5 y más personas ocupadas, según el valor de las ventas, 1992

\begin{tabular}{ll|rr|ccc}
\hline & \multicolumn{2}{|c|}{ Ocupados } & & & \\
\hline $\begin{array}{l}\text { Ventas e } \\
\text { ingresos }\end{array}$ & $\begin{array}{l}\text { Núm. de } \\
\text { empresas }\end{array}$ & Total & $\begin{array}{l}\text { Remu- } \\
\text { nerados }\end{array}$ & $\begin{array}{c}\text { Remunerac. } \\
\text { pagadas }\end{array}$ & $\begin{array}{c}\text { Ventas e } \\
\text { ingresos }\end{array}$ & $\begin{array}{c}\text { Valor } \\
\text { agregado }\end{array}$ \\
\hline Pequeñas & 73.15 & 59.20 & 58.08 & 48.91 & 40.70 & 39.69 \\
Medianas & 23.98 & 32.58 & 33.17 & 38.42 & 36.06 & 35.51 \\
Grandes & 2.87 & 8.22 & 8.75 & 12.66 & 23.24 & 24.80 \\
\hline Total & 100.0 & 100.0 & 100.0 & 100.0 & 100.0 & 100.0 \\
\hline
\end{tabular}

Fuente: Elaboración propia sobre la base de información ya citada.

Si bien no existe proporcionalidad entre el número de empresas y el valor agregado que les corresponde, vemos que el 2.87 por ciento de las empresas, consideradas grandes, controlan el 24.8 por ciento del valor agregado del sector; mientras que el 73.15 por ciento de las empresas, consideradas pequeñas, controlan el 39.69 por ciento del valor agregado. Esta información difícilmente puede sostener la existencia de concentración en el sector, o dicho en otras palabras, para sostener un control significativo de las grandes empresas sobre la actividad del sector.

No obstante lo mencionado anteriormente, sí existe concentración en términos de distribución del ingreso, ya que en el sector la relación remuneraciones sobre el valor agregado es en promedio de 26.02 por ciento, lo cual nos indica que los trabajadores apenas perciben un poco más de la cuarta parte del valor agregado. Esta situación se mejora en las pequeñas empresas, donde la relación remuneraciones/valor agregado es del 32.06 por ciento; se aproxima a la media en las empresas de tamaño medio, y se empeora en las grandes empresas ya que los trabajadores apenas tienen acceso al 13.28 por ciento del valor agregado.

4.3.1. El sector servicios, restaurantes y hoteles, incluyendo a las microempresas

Al observar los datos, incluyendo a la microempresa, vemos que la concentración está en el sector formal de la economía, ya que el 2.63 por ciento de las empresas - pequeñas, medianas y grandes - controlan arriba del 50 por ciento de los ocupados, los remunerados, las remuneraciones pagadas, así como las ventas e ingresos.

\section{Cuadro 20}

Estructura de las empresas del sector servicios, restaurantes y hoteles, según el tamaño de la empresa: micro, pequeña, mediana y gran empresa, 1992

\begin{tabular}{lc|rr|rcc}
\hline & & \multicolumn{2}{|c|}{ Ocupados } & \multicolumn{3}{c}{ Valor en miles de colones } \\
\hline $\begin{array}{l}\text { Tamaño de la } \\
\text { empresa }\end{array}$ & $\begin{array}{l}\text { Núm. de } \\
\text { empresas }\end{array}$ & Total & $\begin{array}{l}\text { Remu- } \\
\text { nerados }\end{array}$ & $\begin{array}{l}\text { Remunerac. } \\
\text { pagadas 1/ }\end{array}$ & $\begin{array}{l}\text { Ventas e } \\
\text { ingresos }\end{array}$ & $\begin{array}{c}\text { Valor } \\
\text { agregado }\end{array}$ \\
\hline Micro 2/ & 94812 & 48865 & 17828 & 202325 & 1898298 & n.d. \\
Pequeñas & 1885 & 30722 & 27568 & 578918 & 2324288 & 1805535 \\
Medianas & 618 & 16902 & 15744 & 454742 & 2059346 & 1615032 \\
Grandes & 74 & 4268 & 4153 & 149893 & 1327537 & 1128679 \\
\hline Total & 97389 & 100757 & 65293 & 1385878 & 7609469 & 4549246 \\
\hline
\end{tabular}

1/: incluye pagos al ISSS y otras remuneraciones. 2/: se usa el mismo criterio ya comentado.

Fuente: Elaborado sobre la base de información de los Censos Económicos, Tomo III pp. 256 y 585-586. 
En este sector - de servicios, restaurantes, etc.--, la microempresa sólo es importante por su número, ya que en el resto de variables la superan el conjunto de empresas con 5 y más ocupados. La microempresa, si bien representa el 97.35 por ciento de las empresas y ocupa al 48.5 por ciento de los ocupados, sólo tiene el 27.31 por ciento de los remunerados, el 14.60 por ciento de las remuneraciones pagadas y el 24.95 por ciento de las ventas e ingresos. No obstante lo anterior, la mi- croempresa es mucho más importante que la gran empresa, la cual apenas ocupa al 4.12 por ciento de los ocupados, tiene el 6.36 por ciento de los remunerados, paga tan sólo 10.82 por ciento de las remuneraciones y realiza un 17.45 por ciento de las ventas e ingresos. Todo lo anterior nos permite sostener que en este sector la gran empresa no es relativamente importante. $\mathrm{La}$ información correspondiente se presenta en los Cuadros 20 y 21.

\section{Cuadro 21}

Estructura porcentual de las empresas del sector servicios, restaurantes y hoteles, según el tamaño de la empresa: micro, pequeña, mediana y gran empresa, 1992

\begin{tabular}{lc|cc|cc}
\hline & & \multicolumn{2}{|c|}{ Ocupados } & & \\
\hline $\begin{array}{l}\text { Tamaño de las } \\
\text { empresas }\end{array}$ & $\begin{array}{c}\text { Núm. de } \\
\text { empresas }\end{array}$ & Total & Remunerados & $\begin{array}{c}\text { Remunerac. } \\
\text { pagadas }\end{array}$ & $\begin{array}{c}\text { Ventas e } \\
\text { ingresos }\end{array}$ \\
\hline Micro & 97.35 & 48.50 & 27.31 & 14.60 & 24.95 \\
Pequeñas & 1.93 & 30.49 & 42.22 & 41.77 & 30.54 \\
Medianas & 0.63 & 15.62 & 24.11 & 32.81 & 27.06 \\
Grandes & 0.07 & 4.12 & 6.36 & 10.82 & 17.45 \\
\hline Total & 100.0 & 100.0 & 100.0 & 100.0 & 100.0 \\
\hline
\end{tabular}

Fuente: Elaboración propia a partir de información ya citada.

\subsubsection{EI subsector financiero}

Sin embargo, en este sector es donde se encuentran las instituciones financieras en las cuales cabría suponer que existe algún grado de concentración. A fin de verificar la veracidad o falsedad de la suposición anterior, procesamos adicionalmente la información que brinda el Censo sobre los Establecimientos Financieros, que corresponde al número 810 de la Clasificación Industrial Internacional Uniforme (CIUU) y que se presenta en los Cuadros 22 y 23.

\section{Cuadro 22}

Estructura de las empresas del subsector financiero, con 5 y más personas ocupadas, según el valor de las ventas, 1992

\begin{tabular}{lc|rr|rrr}
\hline & & \multicolumn{2}{|c|}{ Ocupados } & \multicolumn{3}{c}{ Valor en miles de colones } \\
\hline $\begin{array}{l}\text { Tamaño } \\
\text { empresas }\end{array}$ & $\begin{array}{l}\text { Núm. de } \\
\text { empresas }\end{array}$ & Total & $\begin{array}{c}\text { Remu- } \\
\text { nerados }\end{array}$ & $\begin{array}{c}\text { Remunerac. } \\
\text { pagadas }\end{array}$ & $\begin{array}{c}\text { Ventas e } \\
\text { ingresos }\end{array}$ & $\begin{array}{c}\text { Valor } \\
\text { agregado }\end{array}$ \\
\hline Pequeña & 131 & 4212 & 4099 & 123431 & 785989 & 753385 \\
Mediana & 197 & 5622 & 5432 & 189280 & 943776 & 862130 \\
Grande 1/ & 31 & 2593 & 2573 & 95141 & 653036 & 624114 \\
\hline Total & 359 & 12427 & 12104 & 407852 & 2382801 & 2239629 \\
\hline
\end{tabular}

1/: pequeñas, hasta 1 millón de ventas anuales; medianas, más de 1 millón hasta 10 millones, y grandes, más de 10 millones.

Fuente: Elaborado a partir de información de los Censos Económicos, 1992, Tomo III, p. 257. 
No obstante, no deja de ser interesante que la información obtenida es bastante semejante a la que se presentó para todo el sector antes de incluir a las microempresas. Si bien en el subsector financiero el mayor peso recae en las empresas medianas, en todo el sector de empresas con 5 y más ocupados, el peso lo reciben las pequeñas empresas; en cuanto a la apropiación del valor agregado, la situación entre el sector y el subsector son bastante parecidos, como se puede observar en los Cuadros 19 y 23, respectivamente.

\section{Cuadro 23}

Estructura porcentual de las empresas del subsector financiero, con 5 y más personas ocupadas, según el valor de las ventas, 1992

\begin{tabular}{ll|cc|ccc}
\hline & & \multicolumn{2}{|c|}{ Ocupados } & \multicolumn{3}{c}{ Valor en miles de colones } \\
\hline $\begin{array}{l}\text { Tamaño } \\
\text { empresas }\end{array}$ & $\begin{array}{l}\text { Núm. de } \\
\text { empresas }\end{array}$ & Total & $\begin{array}{c}\text { Remu- } \\
\text { nerados }\end{array}$ & $\begin{array}{c}\text { Remunerac. } \\
\text { pagadas }\end{array}$ & $\begin{array}{c}\text { Ventas e } \\
\text { ingresos }\end{array}$ & $\begin{array}{c}\text { Valor } \\
\text { agregado }\end{array}$ \\
\hline Pequeña & 36.49 & 33.89 & 33.75 & 30.26 & 32.99 & 33.64 \\
Mediana & 54.87 & 45.24 & 44.73 & 46.41 & 39.61 & 38.49 \\
Grande & 8.63 & 20.87 & 21.19 & 23.33 & 27.41 & 27.87 \\
\hline Total & 100.00 & 100.00 & 100.00 & 100.00 & 100.00 & 100.00 \\
\hline
\end{tabular}

Fuente: Elaborado a partir de información del cuadro anterior.

De modo, pues, que si queremos observar la supuesta concentración en la banca, será preciso acudir a información de fuentes diferentes de la que nos ofrece el Censo.

\subsubsection{La concentración en la banca}

Los bancos presentan algún grado de concẹntración de parte de las grandes empresas cuando se trata de los depósitos realizados en el sistema financiero, como se pone de manifiesto en el Cuadro $24^{16}$. En el subsector bancario, la concentración estadístico-estructural se refleja en el hecho de que apenas 3 bancos -Agrícola, Cuscatlán y Salvadoreño- controlan más del cincuenta por ciento de los depósitos, esto es, el 52.6 por ciento para ser más precisos.

Adicionalmente debemos señalar que, en vista de los procesos de centralización del capital ocuridos durante el año pasado y principios de éste, la concentración es mucho mayor que la presentada a partir de la información de la Superintendencia, la cual corresponde al tercer trimestre de 1998.
Como lo señalábamos, han ocurrido procesos de centralización del capital, vía fusión y absorción. Estos procesos se observan en varios hechos, como lo son el que Atlacatl se fusionara con el Banco de Comercio, el décimo y el cuarto banco, respectivamente; o bien que Bancorp lo hiciera con Promérica, bancos ubicados en las posiciones $14 \mathrm{y}$ 15, respectivamente. El Banco Capital es absorbido por Credicorp, un consorcio internacional con asiento en Perú, y de manera semejante ocurre la asociación de Ahorromet -en octavo lugar- con el Scottia Bank de Canadá. Y, finalmente, los bancos Cuscatlán, Salvadoreño, Desarrollo e Hipotecario se reparten lo que fuera el Banco Credisa.

Ciertamente, el proceso de centralización bancario ha sido un hecho inédito en el país, que ha obligado a fusiones internas y externas con tal de no desaparecer, como ha sido la triste historia de algunos bancos, de los cuales el más reciente ejemplo es el del banco Credisa —que ocupaba el sexto lugar en la escala que hemos venido utilizando-.

16. Los depósitos que aparecen en el Cuadro 24 se refieren a: I cuentas corrientes, II ahorros, III títulos de ahorros a menos de 30 días, IV depósitos hasta un año, $\mathrm{V}$ a más de un año plazo, y VI depósitos restringidos, inactivos, etc. 


\section{Cuadro 24}

Depósitos captados al 30 de septiembre, 1998

(en millones de colones)

\begin{tabular}{|c|c|c|c|c|c|c|c|c|c|}
\hline & & I & II & III & IV & V & VI & Total & $\%$ \\
\hline 1 & Agrícola & 1383 & 3641 & 24 & 4422 & 927 & 356 & 10754 & 22.8 \\
\hline 2 & Cuscatlán & 1215 & 2100 & 66 & 3302 & 1443 & 379 & 8507 & 18.0 \\
\hline 3 & Salvadoreño & 770 & 1596 & 4 & 2901 & 249 & 61 & 5583 & 11.8 \\
\hline 4 & Comercio & 444 & 1175 & 1 & 1830 & 437 & 85 & 3973 & 8.4 \\
\hline 5 & Desarrollo & 357 & 690 & 3 & 2190 & 122 & 88 & 3453 & 7.3 \\
\hline 6 & Credisa & 42 & 404 & 1 & 1634 & 209 & 29 & 2322 & 4.9 \\
\hline 7 & Bancasa & 227 & 685 & 42 & 1302 & 148 & 70 & 2476 & 5.3 \\
\hline 8 & Ahorromet & 86 & 575 & 2 & 1292 & 742 & 64 & 2762 & 5.9 \\
\hline 9 & Hipotecario & 188 & 596 & 0 & 862 & 86 & 39 & 1773 & 3.8 \\
\hline 10 & Atlacatl & 23 & 325 & & 901 & 147 & 44 & 1442 & 3.1 \\
\hline 11 & Fomento & 169 & 260 & & 1018 & 1 & 13 & 1463 & 3.1 \\
\hline 12 & Multivalores & 123 & 112 & & 467 & 6 & 4 & 714 & 1.5 \\
\hline 13 & Unibanco & 40 & 65 & & 422 & 0 & 14 & 543 & 1.2 \\
\hline 14 & Bancorp* & 0 & 0 & & 0 & 0 & 0 & 0 & 0.0 \\
\hline 15 & Promérica & 34 & 95 & & 580 & 27 & 15 & 754 & 1.6 \\
\hline 16 & Citibank & 80 & 130 & & 112 & 0 & 17 & 340 & 0.7 \\
\hline \multirow[t]{2}{*}{17} & Capital & 11 & 50 & & 224 & 0 & 2 & 290 & 0.6 \\
\hline & Total & 5199 & 12506 & 146 & 23466 & 4550 & 1288 & 47157 & 100.0 \\
\hline
\end{tabular}

Fuente: Superintendencia del Sistema Financiero.

* En proceso de fusión con Promérica, S.A. y Credisa, que hasta la fecha ya no existe.

4.4. La concentración en la agroindustria: beneficiado de café e ingenios azucareros

Ciertamente estas dos actividades —el algodón y la caña de azúcar - tuvieron muchísima importancia económica en el pasado. De hecho, unidas al cultivo del algodón, constituyeron la principal fuente de divisas y la mayor demanda de trabajadores se encontraba en ellas. Sin embargo, el algodón desapareció en la década pasada y aunque ahora se busca hacerla resurgir, aún no se logra.

\section{Cuadro 25}

Estructura de las empresas del subsector de beneficiado de café, según el valor de la producción bruta, 1992

\begin{tabular}{lc|rr|rrr}
\hline & & Ocupados & \multicolumn{3}{|c}{ Valor en miles de colones } \\
\hline $\begin{array}{l}\text { Tamaño de las } \\
\text { empresas }\end{array}$ & $\begin{array}{l}\text { Núm. de } \\
\text { empresas }\end{array}$ & Total & $\begin{array}{c}\text { Remu- } \\
\text { nerados }\end{array}$ & $\begin{array}{r}\text { Remunerac. } \\
\text { pagadas 1/ }\end{array}$ & $\begin{array}{c}\text { Ventas e } \\
\text { ingresos }\end{array}$ & $\begin{array}{c}\text { Valor } \\
\text { agregado }\end{array}$ \\
\hline $\begin{array}{l}\text { Pequeña } \\
\text { Medianas }\end{array}$ & 51 & 76 & 70 & 486 & 2112 & 679 \\
Grandes 2/ & 37 & 7199 & 7949 & 33514 & 266349 & 79102 \\
Total & 93 & 12302 & 12168 & 121836 & 1399364 & 368582 \\
\hline
\end{tabular}

1/: incluye pagos al ISSS y otras remuneraciones. 2/: pequeña, valor de la producción bruta hasta 1 millón de colones; medianas, más de 1 millón hasta 10 millones, y grandes, más de 10 millones.

Fuente: Elaborado a partir de información de los Censos Económicos, Tomo IV, p. 65, DIGESTYC, 1992. 
Aunque el beneficiado del café no representa toda la actividad cafetalera, si la vinculamos con la exportación tenemos los eslabones más importantes de esta actividad.

\section{Cuadro 26}

Estructura porcentual de las empresas del subsector de beneficiado de café, según el valor de la producción bruta, 1992

\begin{tabular}{ll|rr|rrr}
\hline & & \multicolumn{2}{|c|}{ Ocupados } & \multicolumn{3}{c}{ Valor en miles de colones } \\
\hline $\begin{array}{l}\text { Tamaño de las } \\
\text { empresas }\end{array}$ & $\begin{array}{l}\text { Núm. de } \\
\text { empresas }\end{array}$ & Total & $\begin{array}{c}\text { Remu- } \\
\text { nerados }\end{array}$ & $\begin{array}{c}\text { Remunerac. } \\
\text { pagadas }\end{array}$ & $\begin{array}{c}\text { Producción } \\
\text { bruta }\end{array}$ & $\begin{array}{c}\text { Valor } \\
\text { agregado }\end{array}$ \\
\hline Pequeña & 5.38 & 0.62 & 0.57 & 0.40 & 0.15 & 0.18 \\
Medianas & 54.84 & 40.86 & 40.67 & 27.51 & 19.03 & 21.46 \\
Grandes & 39.78 & 58.52 & 58.75 & 72.10 & 80.82 & 78.35 \\
\hline Total & 100.0 & 100.0 & 100.0 & 100.0 & 100.0 & 100.0 \\
\hline
\end{tabular}

Fuente: Elaboración propia a partir de información ya citada.

Los datos del Cuadro 26 nos indican que el 40 por ciento de los beneficios controlan el 81 por ciento de la producción bruta y casi el 80 por cien- to del valor agregado. Se trata, pues, de una actividad concentrada en las grandes empresas.

\section{Cuadro 27}

Estructura de las exportaciones de café oro, 1994

\begin{tabular}{lcc|cc|rr}
\hline & \multicolumn{2}{c|}{ Núm. de empresas } & \multicolumn{2}{c}{ Exportac. en miles de dólares } & \multicolumn{2}{c}{ Exportac. en miles de colones } \\
\hline & Absoluto & $\%$ & \multicolumn{2}{c|}{ Absoluto } & $\%$ & \multicolumn{2}{c}{ Absoluto } & $\%$ \\
\hline Pequeña & 32 & 38.2 & 13972 & 5.2 & 121696 & 5.2 \\
Medianas & 38 & 45.2 & 91153 & 34.1 & 193942 & 34.1 \\
Grandes 1/ & 14 & 16.6 & 162375 & 60.7 & 1414286 & 60.7 \\
\hline Total & 84 & 100.0 & 267500 & 100.0 & 2329925 & 100.0 \\
\hline
\end{tabular}

1/: pequeñas, menos de 1 millón de dólares; medianas, entre 1 y 5 millones, y grandes, más de 5 millones de dólares.

Fuente: Elaboración propia a partir de información del Banco Central de Reserva, 1994. 1 dólar equivale a 8.71 colones.

Si a los datos del beneficiado le añadimos la información correspondiente a las exportaciones, observamos que el negocio cafetalero se encuentra bastante concentrado: cerca del 17 por ciento de las empresas exportan casi el 61 por ciento del total del café oro. Y precisamente allí -en ese pequeño gru- po de grandes empresas - es donde se concentran los ingresos provenientes del café. Para 1994, 14 exportadores captaron 162.3 millones de dólares ó 1414.2 millones de colones. Es claro que lo anterior nos da una idea del por qué y cómo es que la riqueza se mantiene concentrada en el país. 


\section{Cuadro 28}

Estructura de las empresas del subsector de ingenios azucareros, según el número de personas ocupadas, 1992

\begin{tabular}{lc|cc|ccc}
\hline & & \multicolumn{2}{|c|}{ Ocupados } & \multicolumn{3}{c}{ Valor en miles de colones } \\
\hline $\begin{array}{l}\text { Tamaño de las } \\
\text { empresas }\end{array}$ & $\begin{array}{l}\text { Núm. de } \\
\text { empresas }\end{array}$ & Total & $\begin{array}{c}\text { Remu- } \\
\text { nerados }\end{array}$ & $\begin{array}{c}\text { Remunerac. } \\
\text { pagadas 1/ }\end{array}$ & $\begin{array}{c}\text { Producción } \\
\text { bruta }\end{array}$ & $\begin{array}{c}\text { Valor } \\
\text { agregado }\end{array}$ \\
\hline Pequeña & 0.0 & 0.0 & 0.0 & 0.0 & 0.0 & 0.0 \\
Medianas & 5 & 1975 & 1973 & 34852 & 370000 & 147556 \\
Grandes 2/ & 4 & 2784 & 2784 & 79222 & 728720 & 288334 \\
\hline Total & 9 & 4759 & 4757 & 114074 & 1098361 & 435890 \\
\hline
\end{tabular}

1/: incluye pagos al ISSS y otras remuneraciones. 2/: pequeñas, que comprende hasta 199 ocupados; medianas, de 200 hasta 299 , y grandes, de 300 y más.

Fuente: Elaboración propia a partir de información del Censo Económico, Tomo IV, p. 131.

En cuanto a la agroindustria cañera es interesante observar cómo se concentra en tan sólo 9 ingenios, en su casi totalidad reprivatizados. Atrás han quedado los tiempos en donde la caña de azúcar era procesada de manera artesanal, en un sin número de trapiches a lo largo y ancho de la campiña salvadoreña. Las antiguas carretas que servían para transportar la caña le han dado el paso a los camiones y a las rastras, que ahora se encargan de conducir la caña hacia los grandes ingenios.

\subsection{La concentración en el agro}

No existe en el país información reciente y com- pleta acerca del sector agrícola. La última información general se obtuvo del Censo de 1971, a partir de esa fecha sólo se conocen estudios parciales, investigaciones regionales, encuestas, etc.

En cuanto al agro, éste es el sector que más modificaciones ha experimentado en la década pasada y en la presente, de tal manera que la información que se proporcione acerca de la concentración en el agro debe tomarse con las reservas del caso. Sin embargo, hace algunos años realizamos una investigación documental titulada "El agro salvadoreño: antes y después de la reforma agraria", de la cual obtuvimos información para elaborar el Cuadro 29.

\section{Cuadro 29}

Estructura de las empresas del sector agropecuario, según el tamaño de las explotaciones, 1987

\begin{tabular}{lcccr}
\hline & $\begin{array}{l}\text { Número de } \\
\text { explotaciones }\end{array}$ & Porcentajes & $\begin{array}{l}\text { Superficie en } \\
\text { manzanas }\end{array}$ & Porcentajes \\
\hline Micro & 178369 & 62.3 & 155851 & 8.2 \\
Pequeña & 71675 & 25.0 & 313915 & 16.5 \\
Mediana & 28693 & 10.0 & 585011 & 30.7 \\
Grande 1/ & 7446 & 2.6 & 851575 & 44.7 \\
\hline Total & 286183 & 100.0 & 1906782 & 100.0 \\
\hline
\end{tabular}

1/: microempresas son las explotaciones menores de $2 \mathrm{mz}$; pequeñas, cuando son mayores de $2 \mathrm{mz}$ pero menores de $10 \mathrm{mz}$;; medianas, las de $10 \mathrm{mz}$ pero menores de $50 \mathrm{mz}$, y grandes, las de 50 y más manzanas. PERA, Estudio Nacional del Sector Agropecuario, 1987. 
Dentro de la categoría de grandes empresas caen las asociaciones cooperativas de la fase I de la reforma agraria, las cuales han experimentado, hasta este momento, procesos de parcelación en algunos casos, por tanto es posible que este segmento de grandes empresas controle un menor porcentaje de la tierra. Sin embargo, no deja de ser dramático que el 87 por ciento de las explotaciones, generalmente de propiedad unipersonal y de tenencia familiar, apenas controlen una cuarta parte de la superficie agrícola. De ello se deriva obviamente el hecho opuesto, es decir, que el 2.6 por ciento de las explotaciones controle el 44.7 por ciento de la tierra.

Además de la reforma agraria, la tierra rural ha experimentado los efectos de las lotificaciones, lo cual ha tenido como resultado una mayor atomización de la propiedad que la presentada en el Cuadro 29. Si para entonces el tamaño medio de la explotación se aproximaba a una manzana, en la actualidad, sin duda alguna, es mucho más pequeño. También la estructura de propiedad de la tierra se ha visto afectada por el proceso normal de fragmentación, vinculado a las herencias entre varios miembros de la familia, las transacciones mercantiles y últimamente por el Programa de Transferencia de Tierras (PTT), surgido a raíz del Acuerdo de Paz.

\subsection{La concentración en la generación y distri- bución de electricidad}

El sector se caracteriza por una elevada concentración a tal punto, que son tan sólo 3 las empresas generadoras de electricidad y 5 las distribuidoras, como se puede observar en el Cuadro 30. Es un sector que hasta hace poco se ha abierto a la inversión privada y debido a que es un sector que exige altísimas inversiones y sirve a un mercado bastante reducido, pues no parece posible la existencia de una gran variedad de empresas. Sin embargo, pudiera ampliarse en la medida que vayan ocurriendo nuevas privatizaciones en el campo de la generación de energía termoeléctrica, como lo propone el gobiemo actual.

\section{Cuadro 30}

Estructura de las empresas del subsector electricidad, según el personal ocupado, 1992

\begin{tabular}{|c|c|c|c|c|c|c|}
\hline \multicolumn{2}{|l|}{$\begin{array}{l}\text { Tamaño de las } \\
\text { empresas }\end{array}$} & \multicolumn{2}{|c|}{ Ocupados } & \multicolumn{3}{|c|}{ Valor en miles de colones } \\
\hline $\begin{array}{l}\text { Generadora } \\
\text { de electricidad }\end{array}$ & $\begin{array}{l}\text { Núm. de } \\
\text { empresas }\end{array}$ & Total & $\begin{array}{l}\text { Remu- } \\
\text { nerados }\end{array}$ & $\begin{array}{l}\text { Remunerac. } \\
\text { pagadas } 1 /\end{array}$ & $\begin{array}{l}\text { Producción } \\
\text { bruta }\end{array}$ & $\begin{array}{l}\text { Valor } \\
\text { agregado }\end{array}$ \\
\hline Pequeña & 2 & 71 & 67 & 1402 & 4341 & 3294 \\
\hline Medianas & 0 & 0 & 0 & 0 & 0 & 0 \\
\hline Grandes 2/ & 1 & 2955 & 2955 & 146491 & 1431358 & 922904 \\
\hline Total & 3 & 3026 & 3022 & 147893 & 1435358 & 926198 \\
\hline \multicolumn{7}{|l|}{$\begin{array}{l}\text { Transmisoras y } \\
\text { distribuidoras }\end{array}$} \\
\hline Pequeñas & 1 & 44 & 44 & 762 & 11441 & 2518 \\
\hline Medianas & 1 & 50 & 48 & 1057 & 15096 & 1171 \\
\hline Grandes 2/ & 3 & 1020 & 1020 & 36457 & 824319 & 177493 \\
\hline Total & 5 & 1114 & 1112 & 38276 & 850856 & 181182 \\
\hline
\end{tabular}

1/: excluye cuotas al ISSS y otras prestaciones laborales. 2/: pequeñas, hasta 50 personas ocupadas; medianas, más de 50 hasta 99 , y grandes, de 100 y más.

Fuente: Elaboración propia a partir de información de los Censos Económicos, Tomo IV, pp. 177-178, DIGESTYC, 1992. 
Decíamos que este sector está bastante concentrado y al analizar la información nos damos cuenta que de hecho son 4 empresas - 1 generadora y 3 distribuidoras- las que controlan el sector.

\subsection{La concentración geográfica}

Adicionalmente y como si no fuera suficiente la concentración presentada hasta el momento, ve- mos también que la actividad económica en El Salvador se encuentra concentrada en el reducido espacio geográfico que constituye el Área metropolitana de San Salvador (AMSS). Para ello sólo contamos con información respecto al área de la manufactura y el comercio; sin embargo, pensamos que como una muestra es bastante ilustrativa (Cuadros 31, 32 y 33).

\section{Cuadro 31}

Manufactura diversa, 5 y más personas ocupadas, AMSS, 1992

\begin{tabular}{l|cc|ccc}
\hline & \multicolumn{2}{|c|}{ Ocupados } & \multicolumn{3}{c}{ Miles de colones } \\
\hline $\begin{array}{l}\text { Número } \\
\text { establec. }\end{array}$ & Total & Remunerac. & $\begin{array}{l}\text { Remun. } \\
\text { pagadas }\end{array}$ & $\begin{array}{c}\text { Producción } \\
\text { bruta }\end{array}$ & $\begin{array}{c}\text { Valor } \\
\text { agregado }\end{array}$ \\
\hline 1067 & 66538 & 64979 & 1854476 & 14965726 & 6706568 \\
\hline \multicolumn{5}{c|}{ Como porcentaje del total nacional } \\
\hline 68.0 & 82.9 & 83.4 & 86.3 & 77.7 & 84.7 \\
\hline
\end{tabular}

Fuente: Elaboración propia a partir de Censos Económicos, Vol. V, p. 1.

En el caso de la industria manufacturera formal, más de las tres cuartas partes de los establecimientos, del personal ocupado, de las remunera- ciones, de la producción bruta y del valor agregado se concentran en el área metropolitana (Cuadro 31).

\section{Cuadro 32}

Manufactura diversa incluyendo microempresas, AMSS, 1992

\begin{tabular}{l|cc|ccc}
\hline & \multicolumn{2}{|c|}{ Ocupados } & \multicolumn{2}{c}{ Miles de colones } \\
\hline $\begin{array}{l}\text { Número } \\
\text { establec. }\end{array}$ & Total & Remunerac. & $\begin{array}{l}\text { Remun. } \\
\text { pagadas }\end{array}$ & $\begin{array}{c}\text { Producción } \\
\text { bruta }\end{array}$ & $\begin{array}{c}\text { Valor } \\
\text { agregado }\end{array}$ \\
\hline 3499 & 71256 & 67061 & 1877458 & 15117179 & 6787954 \\
\hline \multicolumn{7}{c}{ Como porcentaje del total nacional } \\
\hline 44.4 & 76.9 & 81.2 & 85.5 & 77.1 & 83.8 \\
\hline
\end{tabular}

Fuente: Elaboración propia a partir de los Censos Económicos, Vol. V, p. 185.

La situación no varía de manera significativa cuando consideramos tanto al sector formal como al informal y aunque ciertamente disminuye la proporción de los establecimientos, no ocurre lo mismo con las otras variables. En el caso de la proporción de ocupados, ésta sigue representando más de las tres cuartas partes. Si bien ha disminuido del 82.9 al 76.9 por ciento, respectivamente, sigue siendo una cifra bastante importante. 
Cuando observamos los datos acerca del comercio formal, en el Cuadro 33, vemos que existe una concentración geográfica todavía mayor que la observada en la manufactura, ya que se aproxi- man los datos al 90 por ciento en casi todas las variables consideradas. $\mathrm{O}$ dicho en otras palabras, la concentración geográfica del comercio se aproxima al 90 por ciento del total.

\section{Cuadro 33}

Comercio al por mayor y menor, 5 y más personas ocupadas, AMSS, 1992

\begin{tabular}{l|cc|ccc}
\hline & \multicolumn{2}{|c|}{ Ocupados } & \multicolumn{3}{c}{ Miles de colones } \\
\hline $\begin{array}{l}\text { Número } \\
\text { establec. }\end{array}$ & Total & Remunerac. & $\begin{array}{l}\text { Remun. } \\
\text { pagadas }\end{array}$ & $\begin{array}{l}\text { Ventas e } \\
\text { ingresos }\end{array}$ & $\begin{array}{c}\text { Valor } \\
\text { agregado }\end{array}$ \\
\hline 1584 & 32688 & 30704 & 876416 & 12713946 & 3550332 \\
\hline \multicolumn{6}{c}{ Como porcentaje del total nacional } \\
\hline 70.9 & 83.6 & 85.1 & 88.6 & 88.5 & 89.6 \\
\hline
\end{tabular}

Fuente: Elaboración propia a partir de los Censos Económicos, Vol. VI, p. 1.

Obviamente, las consecuencias de la concentración geográfica son menos nocivas que la concentración estadístico-estructural; sin embargo, tiene efectos negativos para los sectores populares en tanto que a la población económicamente activa del interior del país se le dificulta o imposibilita, en el peor de los casos, el acceso al empleo y, en consecuencia, a la percepción de ingresos.

De la situación anterior se deriva el hecho de las migraciones hacia el AMSS, las cuales generan una mayor presión sobre los recursos y servicios. Las necesidades de empleo, vivienda, agua, energía eléctrica, educación, salud, transporte, etc. se incrementan y ello produce una desmedida concentración poblacional en un reducido espacio físico, con lo cual se genera otro tipo de problemas propios de las poblaciones hacinadas, sin educación, sin empleo y sin ingresos.

\section{Reflexiones finales}

Resulta bastante sencillo comprender que tanto la concentración estadístico-estructural como la concentración geográfica de la actividad económica son algunos de los factores determinantes de la pobreza, la delincuencia, la drogadicción y de toda una serie mayor de problemas sociales existentes en el país y que hacen cada vez más difícil la vida en él.
La concentración del ingreso -que se explica por la concentración estadístico-estructural en la mayoría de los sectores estudiados, así como por los bajos niveles salariales, la carencia de empleo o de propiedad sobre activos que posibiliten la obtención de ingresos - se traduce o tiene como consecuencia la pobreza estructural para la mayoría de la población. Este tipo de pobreza no tiene un carácter coyuntural y pasajero sino permanente, y su causa es tan profunda que subsiste, incluso, pese a la enorme cantidad de dólares provenientes de las remesas y que mayoritariamente se convierten en consumo. Ahora bien, es innegable que los niveles de pobreza - absoluta y relativa - serían mayores si no se contara con los "pobres dólares"17.

De ahí que no resulta extraño que en la actualidad persistan mayores niveles de pobreza en el área rural, ya que en el interior del país se sufre de la concentración estadístico-estructural, de la concentración geográfica de la actividad económica, así como de la crisis y del abandono que sufre el sector agropecuario, pese a las múltiples protestas y demandas de los diversos sectores sociales afectados.

Los niveles tan elevados de delincuencia en las zonas rurales - asaltos, secuestros, robos de animales y cosechas, etc.- ciertamente sólo se pue-

17. Según informes del Banco Central de Reserva, el año pasado las remesas ascendieron a 1332 millones de dólares. 
Decíamos que este sector está bastante concentrado y al analizar la información nos damos cuenta que de hecho son 4 empresas -1 generadora y 3 distribuidoras - las que controlan el sector.

\subsection{La concentración geográfica}

Adicionalmente y como si no fuera suficiente la concentración presentada hasta el momento, ve- mos también que la actividad económica en El Salvador se encuentra concentrada en el reducido espacio geográfico que constituye el Área metropolitana de San Salvador (AMSS). Para ello sólo contamos con información respecto al área de la manufactura y el comercio; sin embargo, pensamos que como una muestra es bastante ilustrativa (Cuadros 31, 32 y 33).

\section{Cuadro 31}

Manufactura diversa, 5 y más personas ocupadas, AMSS, 1992

\begin{tabular}{l|cc|ccc}
\hline & \multicolumn{2}{|c|}{ Ocupados } & \multicolumn{3}{c}{ Miles de colones } \\
\hline $\begin{array}{l}\text { Número } \\
\text { establec. }\end{array}$ & Total & Remunerac. & $\begin{array}{l}\text { Remun. } \\
\text { pagadas }\end{array}$ & $\begin{array}{c}\text { Producción } \\
\text { bruta }\end{array}$ & $\begin{array}{c}\text { Valor } \\
\text { agregado }\end{array}$ \\
\hline 1067 & 66538 & 64979 & 1854476 & 14965726 & 6706568 \\
\hline 68.0 & 82.9 & 83.4 & 86.3 & 77.7 & 84.7 \\
\hline
\end{tabular}

Fuente: Elaboración propia a partir de Censos Económicos, Vol. V, p. 1.

En el caso de la industria manufacturera formal, más de las tres cuartas partes de los establecimientos, del personal ocupado, de las remunera- ciones, de la producción bruta y del valor agregado se concentran en el área metropolitana (Cuadro 31).

\section{Cuadro 32}

Manufactura diversa incluyendo microempresas, AMSS, 1992

\begin{tabular}{|c|c|c|c|c|c|}
\hline & \multicolumn{2}{|c|}{ Ocupados } & \multicolumn{2}{|c|}{ Miles de colones } & \multirow[b]{2}{*}{$\begin{array}{c}\text { Valor } \\
\text { agregado }\end{array}$} \\
\hline $\begin{array}{l}\text { Número } \\
\text { establec. }\end{array}$ & Total & Remunerac. & $\begin{array}{l}\text { Remun. } \\
\text { pagadas }\end{array}$ & $\begin{array}{c}\text { Producción } \\
\text { bruta }\end{array}$ & \\
\hline 3499 & 71256 & 67061 & 1877458 & 15117179 & 6787954 \\
\hline \multicolumn{6}{|c|}{ Como porcentaje del total nacional } \\
\hline 44.4 & 76.9 & 81.2 & 85.5 & 77.1 & 83.8 \\
\hline
\end{tabular}

Fuente: Elaboración propia a partir de los Censos Económicos, Vol. V, p. 185.

La situación no varía de manera significativa cuando consideramos tanto al sector formal como al informal y aunque ciertamente disminuye la proporción de los establecimientos, no ocurre lo mismo con las otras variables. En el caso de la proporción de ocupados, ésta sigue representando más de las tres cuartas partes. Si bien ha disminuido del 82.9 al 76.9 por ciento, respectivamente, sigue siendo una cifra bastante importante. 
Cuando observamos los datos acerca del comercio formal, en el Cuadro 33, vemos que existe una concentración geográfica todavía mayor que la observada en la manufactura, ya que se aproxi- man los datos al 90 por ciento en casi todas las variables consideradas. $O$ dicho en otras palabras, la concentración geográfica del comercio se aproxima al 90 por ciento del total.

Cuadro 33

Comercio al por mayor y menor, 5 y más personas ocupadas, AMSS, 1992

\begin{tabular}{l|cc|cccc}
\hline & \multicolumn{2}{c}{ Ocupados } & \multicolumn{3}{c}{ Miles de colones } \\
\hline $\begin{array}{l}\text { Número } \\
\text { establec. }\end{array}$ & Total & Remunerac. & $\begin{array}{l}\text { Remun. } \\
\text { pagadas }\end{array}$ & $\begin{array}{c}\text { Ventas e } \\
\text { ingresos }\end{array}$ & $\begin{array}{c}\text { Valor } \\
\text { agregado }\end{array}$ \\
\hline 1584 & 32688 & 30704 & 876416 & 12713946 & 3550332 \\
\hline \multicolumn{6}{c}{ Como porcentaje del total nacional } \\
\hline 70.9 & 83.6 & 85.1 & 88.6 & 88.5 & 89.6 \\
\hline
\end{tabular}

Fuente: Elaboración propia a partir de los Censos Económicos, Vol. VI, p. 1.

Obviamente, las consecuencias de la concentración geográfica son menos nocivas que la concentración estadístico-estructural; sin embargo, tiene efectos negativos para los sectores populares en tanto que a la población económicamente activa del interior del país se le dificulta o imposibilita, en el peor de los casos, el acceso al empleo y, en consecuencia, a la percepción de ingresos.

De la situación anterior se deriva el hecho de las migraciones hacia el AMSS, las cuales generan una mayor presión sobre los recursos y servicios. Las necesidades de empleo, vivienda, agua, energía eléctrica, educación, salud, transporte, etc. se incrementan y ello produce una desmedida concentración poblacional en un reducido espacio físico, con lo cual se genera otro tipo de problemas propios de las poblaciones hacinadas, sin educación, sin empleo y sin ingresos.

\section{Reflexiones finales}

Resulta bastante sencillo comprender que tanto la concentración estadístico-estructural como la concentración geográfica de la actividad económica son algunos de los factores determinantes de la pobreza, la delincuencia, la drogadicción y de toda una serie mayor de problemas sociales existentes en el país y que hacen cada vez más difícil la vida en él.
La concentración del ingreso -que se explica por la concentración estadístico-estructural en la mayoría de los sectores estudiados, así como por los bajos niveles salariales, la carencia de empleo o de propiedad sobre activos que posibiliten la obtención de ingresos - se traduce o tiene como consecuencia la pobreza estructural para la mayoría de la población. Este tipo de pobreza no tiene un carácter coyuntural y pasajero sino permanente, y su causa es tan profunda que subsiste, incluso, pese a la enorme cantidad de dólares provenientes de las remesas y que mayoritariamente se convierten en consumo. Ahora bien, es innegable que los niveles de pobreza - absoluta y relativa - serían mayores si no se contara con los "pobres dólares"17.

De ahí que no resulta extraño que en la actualidad persistan mayores niveles de pobreza en el área rural, ya que en el interior del país se sufre de la concentración estadístico-estructural, de la concentración geográfica de la actividad económica, así como de la crisis y del abandono que sufre el sector agropecuario, pese a las múltiples protestas y demandas de los diversos sectores sociales afectados.

Los niveles tan elevados de delincuencia en las zonas rurales -asaltos, secuestros, robos de animales y cosechas, etc. - ciertamente sólo se pue-

17. Según informes del Banco Central de Reserva, el año pasado las remesas ascendieron a 1332 millones de dólares. 
den explicar, en forma razonable, como consecuencia de la falta de oportunidades para vivir de manera decente. $Y$ es que no sólo hay carencia de empleo, sino que los precios de los productos agrícolas tradicionales no compensan su producción; el deterioro en los términos de intercambio ruralurbano ha sido de tal magnitud, que la producción agrícola en muchos casos no es rentable, con lo cual se está negando a los campesinos su esquema tradicional de vida: producir una parte para el autoconsumo y otra para la venta. Esta parte destinada al mercado es la que les permitía adquirir otros bienes necesarios para vivir y reiniciar el ciclo productivo, además de la caída en la demanda de fuerza de trabajo a causa de la crisis del algodón, la insuficiente recuperación del café y la inexistencia de nuevos cultivos demandantes de grandes contingentes de fuerza de trabajo.

De igual forma al campesino joven se le han cerrado otras vías de inserción al mercado de trabajo que existían en el pasado, tales como el empleo en los cuerpos de seguridad -Tolicía Nacional, Policía de Hacienda y Guardia Nacional- luego de cumplir el servicio militar obligatorio en el cual lograban obtener alguna formación y educación. Pero este circuito se rompió y para un sector de la población rural no se han generado nuevas oportunidades de trabajo formal. Pero como se cuenta con ... tanto la concentración estadísticoestructural como la concentración geográfica de la actividad económica son algunos de los factores determinantes de la pobreza, la delincuencia, la drogadicción y de toda una serie mayor de problemas sociales existentes en el país... tir la pobreza. limita, bloquea o entorpece cualquier intento serio y racional por combatirla dentro de los marcos tradicionales. Ya que cuando existe concentración en el ingreso, existen mercados reducidos y raquíticos que frenan cualquier esfuerzo de crecimiento de la economía que pudiera generar empleo e ingresos en proporciones suficientes como para aba-

Afectar la distribución del ingreso es una tarea clave, necesaria y urgente para cualquier gobierno que se preocupe de la viabilidad de nuestra sociedad, ya que para estimular el desarrollo del sector real de nuestra economía es condición indispensable la mejora en la distribución del ingreso, que posibilitaría un crecimiento endógeno y autosostenido. De no aprovecharse el limitado tiempo que, como última oportunidad, nos están ofreciendo las remesas, ciertamente las posibilidades de alcanzar un desarrollo humano sostenible serán cada vez más remotas para El Salvador.

Por todo lo anterior no deseamos concluir este artículo sin antes señalar una serie de medidas que pueden contribuir a disminuir la concentración del ingreso. Éstas podemos clasificarlas en tres tipos: vía mercado, vía gobierno y vía organismos no gubernamentales.

Las medidas relacionadas con el mercado, el conocimiento de las armas - heredado de la pasada guerra - y se dispone de ellas, pues, nada más fácil que dedicarse a las actividades delictivas generantes de ingresos monetarios.

Ciertamente, la constatación de la concentración estadístico-estructural -que permite suponer con bastante certeza que la concentración de la propiedad es muchísimo mayor, dado que una misma familia posee propiedad sobre más de una gran empresa - no es para sostener la necesidad de una redistribución de la propiedad, sino para argumentar una mejora en la distribución del ingreso, el cual está determinado sólo parcialmente por la concentración de la propiedad.

La concentración en el ingreso no sólo es causa directa de la pobreza, sino que adicionalmente de hecho, no es que se las pretendamos confiar al mercado, sino que tienen que ver con los precios: esto es, primero, mejorar los salarios reales de los trabajadores del campo y de la ciudad, ya que es una vergüenza que el salario medio tienda a igualarse con el salario mínimo; segundo, mejorar los términos de intercambio de los productores agrícolas tradicionales; posibilitar a los productores agrícolas tradicionales la conservación de sus productos de manera que no vendan en cosecha, cuando los precios están deprimidos $y$, finalmente, crear un banco rural inmobiliario orientado a dos líneas fundamentales: crédito de avío y crédito a largo plazo para la compra de tierra e inversión en la misma.

Las medidas de corte gubernamental, sin caer 
en el populismo, tienen que ver con: primero, la asignación de mayores recursos a educación, pero la educación debe de ser formal y técnica desde la primaria, de tal manera que el joven pueda obtener beneficios inmediatos del saber práctico obtenido; segundo, política fiscal seria, agresiva, combativa y correctiva. El mercado contribuye a que se concentre el ingreso, lo cual es una imperfección de toda economía mercantil capitalista; por tanto, el gobiemo debe corregir tal distorsión y al hacerlo buscará captar mayores recursos de quienes tengan mayores ingresos, perseguir a los evasores como auténticos ladrones que son y usar los recursos obtenidos de manera responsable, esto es, invirtiendo en actividades que tengan como resultado la disminución de la desigual distribución del ingreso, por ejemplo en programas de mejora a la productividad, en programas de construcción de vivienda bajo el sistema de ayuda mutua, en salud descentralizada, etc.

$Y$, finalmente, vía organismos no gubernamentales calificados como honestos y capaces, de manera que acompañen de manera eficiente procesos de desarrollo socioeconómico en comunidades organizadas, ya sean urbanas o rurales. Los recursos deben de ser proporcionados por empresas que obtengan ganancias multimillonarias, los cuales serían deducibles de sus impuestos y, además, serían el mejor seguro para continuar lucrando sin riesgos.

San Salvador, febrero de 1999. 